\title{
Plithogenic birleştirme operatörü ve çok kriterli karar verme yöntemleri ile dergi seçimi
}

\author{
Journal selection with Plithogenic aggregation operator and multi-criteria decision-making \\ methods
}

\author{
Abdullah Özçi ${ }^{1}$ \\ ${ }^{1}$ Arş. Gör. Dr., Kahramanmaraş Sütçü İmam Üniversitesi, İktisadi ve İdari Bilimler Fakültesi, İşletme Bölümü, Kahramanmaraş/Türkiye, \\ email: abdullahozcil@ksu.edu.tr, ORCID: https://orcid.org/0000-0001-6304-2986
}

\begin{tabular}{|c|c|}
\hline Makale Bilgisi & $\ddot{O} z$ \\
\hline Araştırma Makalesi & $\begin{array}{l}\text { Dergi seçim süreci kriter ve alternatiflerin yapısı bakımından karar verme konusu içeri- } \\
\text { sinde ele alınabilmektedir. Obiektif dergi göstergelerine ek olarak sübjektif değerlendirme- }\end{array}$ \\
\hline Gönderilme:27 Temmuz 2021 & ler de sürece dâhil edilebilmektedir. Sübjektif kriterlerin taşıdığ çok anlamlılık ve belirsiz- \\
\hline Düzeltme: 7 Kasım 2021 & lik farklı küme teorilerinin de sürece dâhil edilmesine imkân tanımaktadır. Karar verme \\
\hline Kabul: 11 Kasim 2021 & $\begin{array}{l}\text { sürecinin tutarlılı̆̆ını ve gerçek hayat uygulamalarına uygunluğunu arttırmak için bu } \\
\text { calıșada Plithogenic küme teorisinden faydalanılmıștır. Farklı karar vericilere ait değer- }\end{array}$ \\
\hline Anahtar kelimeler: & lendirmelerin Plithogenic operatörler yardımıyla birleştirilerek kriter ağırlıklarının bu- \\
\hline Dergi Secimi, & lunması ve alternatif olarak belirlenen dergilerin sıralanması amaçlanmıstır. Bu amaçla \\
\hline Plithogenic Küme, & Plithogenic küme teorisinin hem ağırlı bulma yöntemlerinden Analitik Hiyerarşi Süreci \\
\hline$C ̧ K K V$ & (Analytic Hierarchy Process-AHP) ile hem de Çok Kriterli Karar Verme (ÇKKV) yöntem- \\
\hline AHP, & lerinden Çok Nitelikli İdeal-Gerçek Karşılaştırma Analizi (Multi Attributive Ideal-Real \\
\hline MAIRCA & Comparative Analysis-MAIRCA) yöntemi ile birlikte kullanımı örneklendirilmiştir. \\
\hline
\end{tabular}

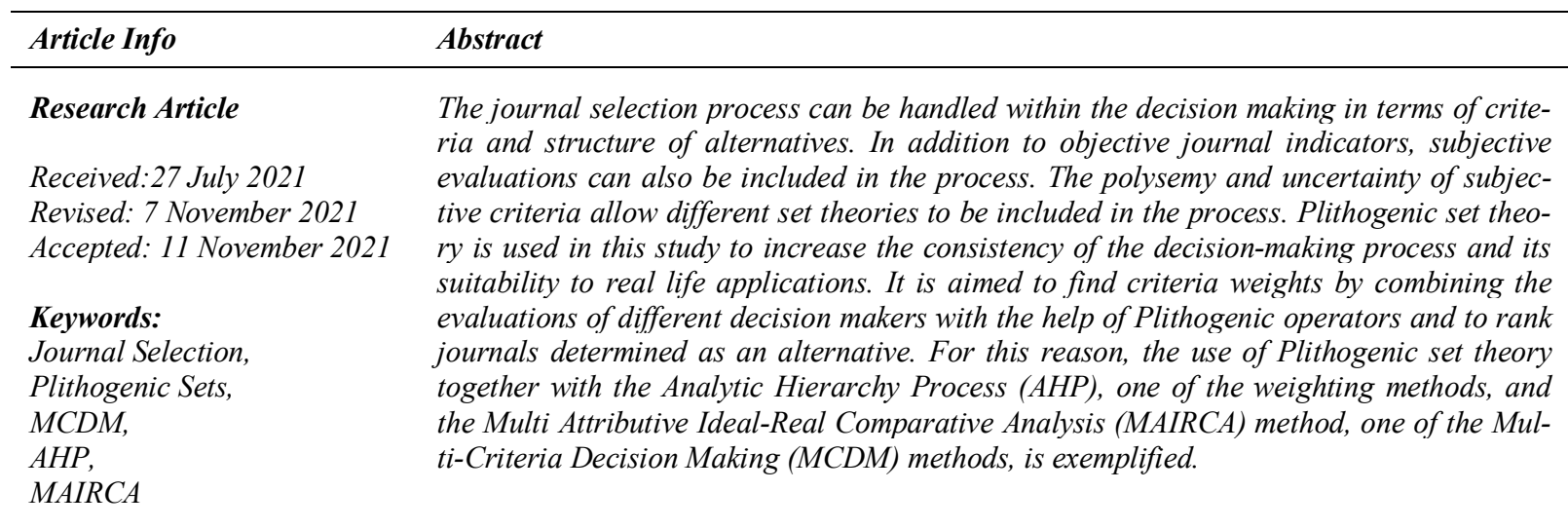

\section{Giriş}

Bilimsel dergi yayınları hem bireylerin hem de üniversitelerin performans göstergelerinden biri olarak kabul edilmektedir. Bu gösterge üniversiteleri ve araştırmacıları sıralamak için yaygın olarak kullanılan performans ölçütlerinden biridir (Unutmaz Durmuşoğlu ve Durmuşoğlu, 2021:522). Bu nedenle bilimsel dergi yayınları küresel anlamda bireyler ve kurumlar açısından önem taşımaktadır. Günümüzde dünyanın çeşitli yerlerinde araştırmacılar; iş bulmak, daha üst sıralara yükselmek, bilgi ve deneyimlerini dünyanın dört bir yanındaki meslektaşları ile paylaşmak ve kendi alanlarına katkıda bulunarak mevcut bilimsel bilgiyi ilerletmek için uluslararası

\footnotetext{
* Bu araştırma insanlarla veya insanlar üzerinde yapılan deney, inceleme ve alan araştırması kapsamında olmadığı için Etik Kurulu Onay belgesi gerekmemektedir. Tüm sorumluluk yazara aittir.
}

Kaynak göster: Özçil, A. (2022). Plithogenic birleştirme operatörü ve çok kriterli karar verme yöntemleri ile dergi seçimi. International Journal of Social Sciences and Education Research, 8 (1), 1-20. DOI: https://doi.org/10.24289/ijsser.974976 
alanda yayın yapmaktadırlar (Uysal, 2012: 51-52). Ayrıca araştırma fonu kazanımı da bilimsel yayın yapma sonuçlarından biridir. Araştırmacılar kaliteli ve nitelikli yayın yaparak hem YÖK'ün hem de üniversitelerin belirlediği kariyerde yükselme şartlarını sağlamaya çalışmaktadırlar. Dolayısıyla araştırmacılar, çalışmaları için en uygun dergiyi seçme kararını verirken birden fazla kriteri göz önünde bulundurmaktadırlar (Hamurcu ve Eren, 2017:55).

Akademisyenler tipik olarak kariyerleri boyunca dergi seçim kararını tekrar tekrar verirler. Gönderme ve değerlendirme süreci çok zaman alabildiğinden ve akademik araştırmacıların eş zamanlı olarak yalnızca tek dergiye makale gönderme kuralı olduğundan dolayı derginin doğru seçilmesi, yayın başarısı için çok önemlidir (Knight ve Steinbach, 2008:60). Ayrıca dergi seçimi, okuyuculara faydası, derginin kalitesi ve ilgili alana veya disipline uygunluğu açısından da önemlidir (He ve Pao, 1986: 405). Dergilerin erişilebilirliği, algılanan itibarları ve etkili yaygınlaştırma politikaları hem yazarlara hem de okuyuculara sağladıkları teknik altyapıya bağlı olarak yayınlar arasında büyük farklılıklar gösterebilen bir husustur. Bu bağlamda dergi seçim kararı her zamankinden daha önemli ve artan teknolojik imkânlar sayesinde alternatiflerin de çok fazla sayıda olması nedeniyle her zamankinden daha zor hale gelmiştir. Sonuçta çalışmanın yer aldığı dergiler, gelecekteki kariyer yolunu ve beklentileri şekillendirmektedir ve araştırmanın görünürlüğünü ve etkisini belirlemektedir (Dalton, 2013:33).

Araştırmacılarının yayın yapma gerekçelerinin farklılığı yanında yayın tercihlerini etkileyen faktörler çok çeşitlidir. Bu faktörler kişisel amaçlara bağlı olan iç faktörlerin yanı sıra daha geniş anlamda dış faktörlerden de etkilenmektedir. Araştırmalar hakem kurulu, inceleme sürecinin kalitesi, algılanan itibar ve konuya uygunluk gibi daha geleneksel ve disipline özgü iç faktörlere ek olarak açık erişim hareketi ve derginin nicel göstergeleri gibi dış faktörlere odaklanmaktadırlar (Dalton, 2013: 34). Araştırmacının hem iç hem de dış faktörlere bağlı kriterler ile birçok alternatif arasından bilimsel dergi seçim süreci doğası gereği bir karar verme problemidir (Li ve Zhao, 2014: 670).

Karar verme, karar vericinin deneyimine ve tercihlerine dayalı olarak bir dizi alternatif arasından en uygun kararın seçildiği kritik bir süreçtir. Çok Kriterli Karar Verme (ÇKKV), karar verme biliminin bir dalıdır (AbdelBasset, Mohamed, Zaied, Gamal ve Smarandache, 2020: 2). ÇKKV'nin amacı, bir dizi kriteri karşılayan en uygun alternatifi belirlemektir (Abdel-Basset, Ding, Mohamed ve Metava, 2020: 197). ÇKKV kapsamında geliştirilen metodolojilerle dört ana farklı karar problemi; sıralama, seçim, sınıflama ve açıklama olarak ele alınmaktadır (Abastante vd., 2019: 111). Birden çok kriteri ilgilendiren karar problemlerini oluşturmada ve çözmede bireylere yardımcı olan çok sayıda ÇKKV tekniği vardır. Her tekniğin kendine ait özellikleri vardır ve hiçbiri en iyisi değildir. Uygun ÇKKV tekniği, problem yapısına uygun olarak belirlenmelidir (Abdel-Basset, Mohamed, Zaied, Gamal ve Smarandache, 2020: 2).

Dergi seçim süreci kaçınılmaz olarak değerlendiricilerin öznel yargılarını içerir. Değerlendiriciler, yargılarını açıklamak için mesleki bilgi ve deneyimlerine göre dilsel değişkenlerini kullanırlar (Li ve Zhao, 2014: 670). Bu nedenle, klasik küme teorisine ek olarak farklı küme teorileri dergi seçim problemine çözüm arayışına entegre edilmiştir. Klasik küme teorisi günlük hayattaki problemlerin çözümünde yetersiz kalmaktadır. Gerçek hayatta, değişkenler için herhangi bir üyelik derecesine ilişkin belirsizlik varsayımı olabilmektedir. Bu durumda, Zadeh (1965) tarafından formüle edilen bulanık kümeler ve bulanık mantık, belirsiz olan koşulları tanımlamak için uygun matematiksel araç haline gelmektedir (Gomathy vd., 2020: 453). Birçok araştırmacı bu tür belirsizlik içeren problemlere Bulanık küme teorisini uygulamışlardır. Ancak;

- Atanassov (1986) tarafindan önerilen Sezgisel Bulanık küme (Intuitionistic Fuzzy Set),

- Smarandache (2005) tarafindan önerilen Neutrosophic küme,

- Yager (2013) tarafından önerilen Pythagorean Bulanık küme,

- Smarandache (2017) tarafindan önerilen Plithogenic küme,

olmak üzere bazı küme teorileri belirsizliği, bulanık kümelerden daha iyi bir şekilde ele almaktadır (Gayen vd., 2020: 214).

Literatürde Plithogenic birleştirme operatörü, ÇKKV yöntemlerinde karar verici değerlendirmelerini birleştirmek amacıyla kullanılmaktadır. Abdel-Basset ve Mohamed (2020) işletmelerin sürdürülebilir tedarik zinciri risklerinin belirlenmesini ve sıralanmasını Plithogenic birleştirme operatörü, Kriterler arası Korelasyon Yoluyla Kriterlerin Önemi (CRiteria Importance Through Intercriteria Correlation-CRITIC) ve İdeal Çözüme Benzerlik Yoluyla Tercih Siralama Tekniği (Technique for Order Preference by Similarity to Ideal Solution-TOPSIS) yöntemleri ile ele almıştır. Alternatif olarak belirlenen üç risk türü otuz altı kriter açısından ve üç karar verici tarafından değerlendirilmiş̧ir. 
Grida vd. (2020) pandemi önleme politikalarının ağırlıklandırılmasını ve tedarik zincirine etkilerinin sıralanmasını Plithogenic birleştirme operatörü, En İyi-En Kötü Yöntemi (Best-Worst Method-BWM) ve TOPSIS yöntemleri ile yapmıştır. Politika önerileri olarak üç alternatif, dokuz kriter açısından dört karar verici tarafından değerlendirilmiştir. Abdel-Basset, Mohamed, Elhoseny ve Chang (2020) tarafindan akıllı afet müdahale sistem seçim problemine ait on dört kriterin ağırlık değerleri Plithogenic birleştirme operatörü ve Analitik Hiyerarşi Süreci (Analytic Hierarchy Process-AHP) yöntemi kullanılarak belirlenmiştir. Üç karar vericinin olduğu çalışmada TOPSIS yöntemi ve Çok Kriterli Uzlaşık Sıralama Yöntemi (VIšekriterijumsko KOmpromisno Rangiranje-VIKOR) ile beş alternatife ait sıralama sonuçları karşılaştırılmıştır.

Abdel-Basset, Ding, Mohamed ve Metawa (2020) çelik endüstrisi firmalarına ait finansal performanslarının değerlendirmesini Plithogenic birleştirme operatörü, AHP, TOPSIS ve VIKOR yöntemleri ile yapmıştır. Alternatif olarak belirlenen on firmaya ait yirmi finansal gösterge üç karar verici tarafından değerlendirilmiştir. Özçil vd. (2020) otomotiv endüstrisinde yeşil tedarikçi seçim problemini Plithogenic birleştirme operatörü ve Çok Nitelikli İdeal-Gerçek Karşılaştırma Analizi (Multi Attributive Ideal-Real Comparative Analysis- MAIRCA) yöntemi ile ele almıştır. Literatürden alınan bu seçim probleminde üç karar vericinin dokuz kritere göre dört alternatif hakkındaki görüşleri yer almaktadır. Abdel-Basset, Mohamed, Zaied, Gamal ve Smarandache (2020) tedarik zinciri problemlerinden depo (üretim tesisi) yeri seçiminde kriterlerin ağırlık değerlerinin belirlenmesi, Plithogenic birleştirme operatörü ve BWM yöntemi ile yapılmıştır. İki farklı durum olarak altı ve dört kriter, dört ve üç karar verici tarafından değerlendirilmiştir.

Abdel-Basset, El-Hoseny, Gamal ve Smarandache (2019) beş hastaneyi, tıbbi bakım sistemleri ve hizmetlerine göre on bir kriter açısından üç karar verici değerlendirmeleri kullanılarak Plithogenic birleştirme operatörü ve VIKOR yöntemleri ile sıralamıştır. Ayrıca Plithogenic işlemlerin veya farklı yöntemlerin de olduğu çalışmalar incelenmiştir. Quek vd. (2020) Neutrosophic işlemleri kullanarak, bir karar verici ve on üç kritere göre yedi alternatif yerleşim yeri arasından seçim problemine Plithogenic Entropi yöntemi ile çözüm önerisi yapmıştır. Korucuk vd. (2020) lojistik sektöründe inovasyon yeteneği boyutlarına ait dokuz karar vericinin değerlendirmelerinden faydalanarak dokuz kriterin Plithogenic CRITIC yöntemi ile ağırlık değerlerini belirlemiştir. Öztaş vd. (2020) otel performanslarını Plithogenic birleştirme operatörü ve Veri Zarflama Analizi (VZA) yöntemleri ile değerlendirmiştir. Alternatif olarak belirlenen on altı otel işletmesi üç karar verici grubun değerlendirmeleri, dört girdi ve iki çıktı değişkeni kullanılarak sıralanmıştır.

Dergi seçim sürecine çözüm üretmek ve karar verme modeli önerisinde bulunmak amaciyla literatürde yapılan çalışmalar da incelenmiştir. Unutmaz Durmuşoğlu ve Durmuşoğlu (2021) tarafindan dergi seçim sürecini etkileyen kriterler etki faktörü, beş yıllık etki faktörü, makale etkisi/özfaktör, kabul oranı, ilk karar süresi ve yayınlanma süresi olarak ele alınmıştır ve TOPSIS yöntemi ile dokuz alternatif sıralanmıştır. Hamurcu ve Eren (2017) araştırmacıların akademik çalışmalarını yayımlatmak için SCI (Science Citation Index) indekste olan altı alternatif dergi arasından beş temel (Değerlendirme Süreci, Derginin Prestiji, Dergi Sınıfları, Mali ve Genel Özellikler), yirmi alt kritere göre seçim yapma sürecini ele almışlardır. Hem kriter ağırlıklarının belirlenmesi hem de alternatif seçimi Analitik Ă̆ Süreci (Analytic Network Process-ANP) yöntemi ile yapıllmıştır.

Li ve Zhao (2014) yetmiş yedi dergiyi, objektif ve sübjektif kriterler içeren sezgisel bulanık bileştirme operatörleri ile kriter ağılıklarının belirlendiği ve sıralama için TOPSIS yönteminin kullanıldığı model ile değerlendirmişlerdir. Objektif kriterler olarak dergilere ait üç farklı gösterge (Etkililik, Toplam Etki ve Güncellik) ve sübjektif kriterler olarak beş farklı değişken (Genel İzlenim, Teknolojik Uygunluk, Uzun Vadeli Varlığını Sürdürebilirlik, Yeni Teoriler Oluşturma ve Mevcut Teorilere Katkı) kullanmışlardır. Sübjektif kriterlerin beş farklı karar verici tarafından değerlendirilmesi ile model sonuçları ve H-indeks ile dergi sıralaması sonuçları karşılaştırılmıştır.

Dalton (2013) tarafından dergi seçim süreci hem araştırmacılar hem de kütüphaneciler açısından değerlendirilerek çıkarımsal istatistiki yöntemler (Mann Whitney-U Testi) ile karşılaştırılmıştır. Yirmi bir kritere ilişkin veriler anket yöntemi ile beşli Likert ölçeği kullanılarak üç yüz yirmi altı kişiden elde edilmiştir. Uysal (2012) tarafından dergi seçme sürecine yönelik önemli hususlar; derginin hakemli olup olmadığı, kapsam ve amaçları, belirli bir gruba yönelik yayın yapıp yapmadığı, okuyucu kitlesi, metodoloji tercihleri, güvenilirliği, saygınlı̆̆ı, etki faktörü ve kabul edilme olasılığı, görünürlük ve erişilebilirliği, yayınlanma sıklığı ve süresi, sözcük/sayfa sınırı gibi biçimsel faktörler olarak belirlenmiştir.

Knight ve Steinbach (2008) araştırmacılara dergi seçiminde yardımcı olabilecek otuz dokuz farklı faktör içeren bir model önerisinde bulunmuşlardır. Bu faktörler beş temel grupta (Kabul Olasılığı, Derginin Güvenilirliği ve Saygınlığı, Makalenin Potansiyel Etkisi \& Görünürlüğü, Gönderinin Yayınlanma Süresi ve Felsefi \& Etik 
Konular) sınıflandırılmıştır. Klingner vd. (2005) iyi bir derginin özelliklerini Yüksek Tiraj, Düşük Kabul Oranı, Tanınmış editörler ve Yayın Kurulu Üyeleri, Uzun Bir Atıf Ömrü, Yüksek Bir Etki Faktörü ve Yüksek Görünürlük olarak özetlemişlerdir. Schniederjans ve Santhanam (1989) kütüphaneler için dergi seçim sürecini 0-1 Hedef Programlama ile açıklayıcı bir örnekte altı kritere (Bütçe, Alanındaki Atıf Sayısı, İlgili Alanlardaki Atıf Sayısı, Derginin Fakülte Değerlendirmesi, Derginin Kullanımı ve Derginin Ulaşılabilirliği) göre on beş dergi alternatifini iptal etme açısından değerlendirmişlerdir.

$\mathrm{Bu}$ çalışmada da sübjektif ve objektif değerlendirmeleri içeren dergi seçim problemi bir ÇKKV problemi olarak ele alınmıştır. Dilsel değişkenlerle ifade edilen ve belirsizlik içeren sübjektif değerlendirmeler Plithogenic küme teorisi ile bütünleşik olarak kullanılmıştır. Ayrıca bu çalışma ile;

- Dergi seçimi konusunda yapılmış çalışmalara katkıda bulunarak yazarlara dergi seçimi konusunda yöntem önerisinde bulunmak,

- Plithogenic küme teorisinin birleştirme işlemi sonrası diğer yöntemlerde kullanımını AHP ve MAIRCA yöntemleri ile örneklendirmek,

- Plithogenic küme teorisi işlemlerinin kullanımının Türkçe literatürde de yer almasına katkıda bulunmak, amaçlanmaktadır.

Çalışmanın devamı olarak ikinci bölümde Plithogenic kümeler, Plithogenic kümelerde kullanılan Neutrosophic sayılar ve Plithogenic işlemler tanıtılmıştır. Çalışmanın üçüncü bölümünde ise literatürde yaygın olarak kullanılan ve çalışmanın kapsamına dâhil edilen ÇKKV yöntemlerinden AHP ve MAIRCA yöntemleri anlatılmıştır. Dördüncü bölümde dergi seçim problemi, öznel değerlendirmeler için Plithogenic birleştirme operatörleri, kriterlerin ağırlık değerlerinin belirlenmesi için AHP yöntemi ve alternatifleri sıralamak için MAIRCA yöntemi kullanılarak ele alınmıştır. Sonuç bölümünde ise dergi seçim sürecine yönelik karar verme modelinden ve gelecek çalışmalara yönelik öneri ve tavsiyelerden bahsedilmiştir.

\section{Yöntem}

Günlük hayatta karşılaşılan durumların dilsel değişkenler ile ifade edildiği karmaşıklık ve belirsizlik özelliklerinin matematiksel olarak modellenmesinde Plithogenic küme teorisi kullanılmaktadır. Plithogenic küme teorisi yapısı gereği farklı karar verici özelliklerinin karar verme sürecine dâhil edilmesine imkân tanımaktadır. Bu nedenle Plithogenic küme teorisinden yaygın kullanım alanlarından biri olan ÇKKV problemlerine çözüm arayışında faydalanılmıştır.

\subsection{Plithogenic küme}

Plithogeny, çelişkili veya çelişkili olmayan çoklu olguların bileşiminden yeni olguların türetilmesi, geliştirilmesi ve ilerlemesini ifade eder. Plithogenic kümeler Samarandache (2017) tarafindan tanıtılmıştır. Plithogenic küme; klasik, bulanık, sezgisel bulanık ve Neutrosophic kümelerin bir genellemesi olarak öğelerin öznitelik değerleriyle karakterize edildiği bir kümedir (Abdel-Basset, Mohamed, Zaied ve Smarandache, 2019: 2). Klasik ve bulanık kümeler üyelik derecesi ile sezgisel bulanık kümeler hem üyelik hem de üye olmama ile, Neutrosophic kümeler ise üyelik, üye olmama ve belirsizlik ile karakterize edilmektedir (Smarandache, 2018: 155). Genel olarak bir Plithogenic küme ise dört veya daha fazla öznitelik değeriyle karakterize edilen elemanlara sahip olabilmektedir (Smarandache, 2017: 15). Plithogenic küme bileşenleri en az bir özellik ile tanımlanan ve her bir özniteliğin çok sayıda unsuru olabilen bir kümedir (Gomathy vd., 2020: 454).

Plithogenic kümeler, öznitelik değerleri açısından karakterize edilen unsurlardan oluşur. Çelişki Derecesi kullanılarak sonuçların doğruluğu artırılabilir (Korucuk vd., 2020: 122). Neutrosophic küme teorisinin gelişmişi olan ve $P$ ile temsil edilen bir Plithogenic küme (P, A, V, d, c) olarak gösterilmektedir. Öznitelik sayısı $A$ $\left(A=\left\{a_{1}, a_{2}, \ldots, a_{m}\right\}, m \geq 1\right)$ olmak üzere $m$ tanedir ve her özelliğin $V\left(V=\left\{v_{1}, v_{2}, \ldots, v_{n}\right\}, n \geq 1\right)$ tane değeri vardır (Abdel-Basset, Mohamed, Zaied, Gamal ve Smarandache, 2020: 5). Her öznitelik verilen kritere aitliği tanımlayan eklenti derecesi (a degree of appurtenance) $d$ ile ifade edilir. Her ikili özniteliğin arasındaki benzerlik ve karşıtlık miktarı, Çelişki Derecesi (a degree of contradiction) $c$ ile karakterize edilir (Quek vd., 2020: 15).

Her öznitelik değeri, $v_{j}$ ile en önemli nitelik değeri $v_{D}$ arasında olan kendi Çelişki Derecesi değerine $c\left(v_{j}, v_{D}\right)$ sahiptir. Nitelikler arasındaki Çelişki Derecesi, modelin daha doğru sonuçlar elde etmesine yardımcı olur (Abdel-Basset, Mohamed, Zaied ve Smarandache, 2019: 2) Özellikle Çelişki Derecesi, her bir özniteliğin değerleri ile baskın öznitelik arasındaki farkı belirler. Bu özelliği ile daha gerçekçi sonuçlar elde edilmesi açısından problemin çözümüne yardımcı olur (Öztaş vd., 2020: 743-744). Ancak Çelişki Derecesi değerinin mevcut olmadığı 
durumlarda varsayılan olarak sıfır kabul edilir. Baskın öznitelik değerinin dikkate alınmayacağı veya birçok baskın öznitelik değeri olabileceği durumlar da vardır. Bu gibi durumlarda ya Çelişki Derecesi işlevi bastırılır ya da öznitelik değerleri arasında başka bir ilişki işlevi kurulmalıdır (Smarandache, 2017: 23). Eklenti derecesi veya Çelişki Derecesi Bulanık, Sezgisel Bulanık veya Neutrosophic sayı olarak ifade edilebilir. Çelişki Derecesi fonksiyonu Plithogenic toplama operatörleri (kesişim, birleşim, tümleyen, kapsama, eşitlik) için doğruluk seviyesinin arttırılmasına yardımcı olur (Abdel-Basset, Mohamed, Zaied, Gamal ve Smarandache, 2020: 2).

\subsubsection{Neutrosophic küme}

Neutrosophic küme, Bulanık Kümelerin ve Sezgisel Bulanık Kümelerin bir genellemesidir. Günlük yaşamda uygulanan bazı belirsizlikler, tutarsılıklar ve eksik bilgileri işlemek için güçlü bir araçtır. Neutrosophic kümeler üyelik, belirsizlik ve üye olmama fonksiyonları gibi üç bileşenle ilgilenir. Gerçek hayattaki problemlerin üstesinden gelmek için çok yararlı bir uygulamadır. Ancak yalnızca üç öznitelik değerine uygulanabilir (Gomathy vd., 2020: 454).

$X$ bir dizi eleman ve $x \in X$ olsun. Herhangi bir $A$ Neutrosophic kümesi, doğruluk $[T(x)]$, belirsizlik $[I(x)]$ ve yanlışlık $[F(x)]$ üyelik fonksiyonlarından oluşur. Bu değerler ]0,1[ aralığındadır. Üyelik işlevlerinin toplanmasında herhangi bir kısıtlama yoktur. Ancak $0 \leq \operatorname{sup~} \mathrm{T}(\mathrm{x})+\sup \mathrm{I}(\mathrm{x})+\sup \mathrm{F}(\mathrm{x}) \leq 3$ şartı sağlanmalıdır (AbdelBasset ve Mohamed, 2020: 4).

$\operatorname{Doğruluk}[T(x)]$, belirsizlik $[I(x)]$ ve yanlışlık $[F(x)]$ üyelik fonksiyonlarından oluşan $\tilde{a}=\left(a_{1}, a_{2}, a_{3}\right) ; \alpha, \theta, \beta$ tek değerli üçgensel Neutrosophic sayı Denklem (1-3)'te gösterilmiştir.

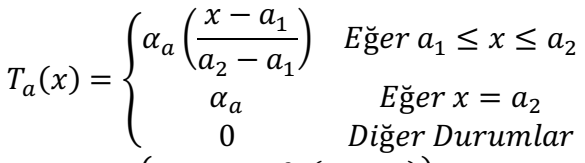

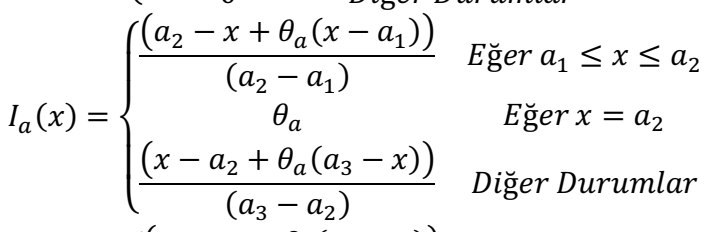

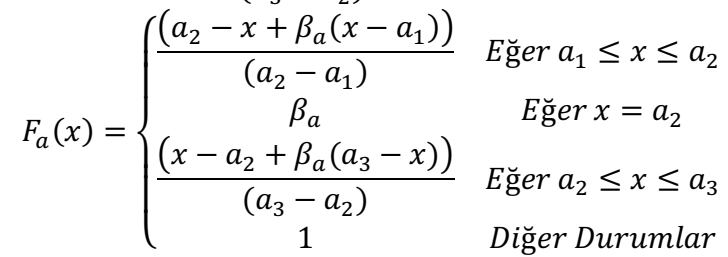

Denklem (1-3)'te gösterilen $\alpha_{a}, \theta_{a}$ ve $\beta_{a}$ elemanları [0,1] aralığındadır ve sırasıyla en yüksek doğruluk, en düşük belirsizlik ve en düşük yanlışlık üyelik derecelerini göstermektedir (Abdel-Basset, Mohamed, Elhoseny ve Chang, 2020: 4).

\subsubsection{Plithogenic kesişim ve birleşim operatörleri}

Plithogenic toplama operatörleri (kesişim, birleşim, tamamlama, dâhil etme, eşitlik) öznitelik değerleri arasındaki Çelişki Dereceleri'ne dayanır. Kesişim ve birleşim işlemleri bulanık $t_{\text {norm }}$ ve $t_{\text {conorm }}$ operatörlerinin doğrusal kombinasyonlarıdır (Smarandache, 2017: 23).

Neutrosophic sayılar kullanılarak Plithogenic kümelerdeki kesişim ve birleşim işlemleri için $\tilde{a}=\left(a_{1}, a_{2}, a_{3}\right)$ ve $\tilde{b}=\left(b_{1}, b_{2}, b_{3}\right)$ olmak üzere iki Plithogenic sayı olsun. Plithogenic kesişim işlemi Denklem (4)'te gösterilmiştir (Smarandache, 2017: 32).

$$
\begin{aligned}
& \tilde{a} \wedge_{p} \tilde{b}=\left(\left(a_{i 1}, a_{i 2}, a_{i 3}\right), 1 \leq i \leq n\right) \wedge_{p}\left(\left(b_{i 1}, b_{i 2}, b_{i 3}\right), 1 \leq i \leq n\right) \\
& =\left(\left(a_{i 1} \wedge_{p} b_{i 1}\right), \frac{1}{2}\left[\left(a_{i 2} \wedge_{p} b_{i 2}\right)+\left(a_{i 2} \vee_{p} b_{i 2}\right)\right], a_{i 3} \vee_{p} b_{i 3}\right), 1 \leq i \leq n
\end{aligned}
$$

Plithogenic birleşim işlemi ise Denklem (5)'te gösterilmiştir (Smarandache, 2017: 33).

$$
\begin{aligned}
& \tilde{a} \vee_{p} \tilde{b}=\left(\left(a_{i 1}, a_{i 2}, a_{i 3}\right), 1 \leq i \leq n\right) \vee_{p}\left(\left(b_{i 1}, b_{i 2}, b_{i 3}\right), 1 \leq i \leq n\right) \\
& =\left(\left(a_{i 1} \vee_{p} b_{i 1}\right), \frac{1}{2}\left[\left(a_{i 2} \wedge_{p} b_{i 2}\right)+\left(a_{i 2} \vee_{p} b_{i 2}\right)\right], a_{i 3} \wedge_{p} b_{i 3}\right), 1 \leq i \leq n
\end{aligned}
$$


Denklem (4) ve (5)'te gösterilen $\wedge_{p}$ ve $\vee_{p}$ işlemleri sırasıyla Denklem (6) ve (7)'de gösterilmiştir (AbdelBasset, Mohamed, Elhoseny ve Chang, 2020: 5).

$$
\begin{aligned}
& a_{i 1} \wedge_{p} b_{i 1}=\left[1-c\left(v_{D}, v_{1}\right)\right] \cdot t_{\text {norm }}\left(a_{i 1} \wedge_{F} b_{i 1}\right)+c\left(v_{D}, v_{1}\right) \cdot t_{\text {conorm }}\left(a_{i 1} \vee_{F} b_{i 1}\right) \\
& a_{i 1} \vee_{p} b_{i 1}=\left[1-c\left(v_{D}, v_{1}\right)\right] \cdot t_{\text {conorm }}\left(a_{i 1} \vee_{F} b_{i 1}\right)+c\left(v_{D}, v_{1}\right) \cdot t_{\text {norm }}\left(a_{i 1} \wedge_{F} b_{i 1}\right)
\end{aligned}
$$
tedir.

Denklem (6) ve (7)'deki $t_{\text {norm }}\left(a_{i 1} \wedge_{F} b_{i 1}\right)=a_{i 1} . b_{i 1}$ ve $t_{\text {conorm }}\left(a_{i 1} \vee_{F} b_{i 1}\right)=a_{i 1}+b_{i 1}-a_{i 1} . b_{i 1}$ 'i simgelemek-

Tek değerli Neutrosophic sayıların klasik küme sayılarına dönüştürülmesinde literatürde farklı eşitlikler kullanılmaktadır. Bu çalışmada Denklem (8)'in kullanılması tercih edilmiştir (Kutlu Gündoğdu ve Kahraman, 2020: 4618).

$$
C(\tilde{a})=0,6+0,4 a_{1}-0,2 a_{2}-0,4 a_{3}
$$

\section{3. Çok kriterli karar verme}

Performans değerlendirme, sıralama veya gruplama problemlerinin çoğu ÇKKV olarak kabul edilir. Bu problemler değerlendirilmesi gereken alternatiflerin performansını ölçecek bir dizi tanımlanmış kriterden oluşur. Birçok çalışma farklı ÇKKV yöntemlerini kullanarak çeşitli problemleri çözer (Abdel-Basset, Mohamed, Elhoseny ve Chang, 2020: 3).

ÇKKV yöntemlerinin iki tür tekniği vardır. Bunlardan ilki, tercihlere dayalı olan AHP, BWM, Eleme ve Seçim Yansitan Gerçeklik (ELimination Et Choix Traduisant la REalité-ELECTRE), Kategorik Esaslı Değerlendirme Tekniği ile Yakınlık Ölçümü (Measuring Attractiveness by a Categorical Based Evaluation TecHniqueMACBETH), Olası Tüm Alternatiflerin Potansiyel Olarak Tüm İkili Sıralamaları (Potentially All Pairwise RanKings of all possible Alternatives-PAPRIKA) vb. gibi yöntemlerdir. İkincisi ise matematiksel işlemlere dayalı olan Entropy, CRITIC, Basit Toplamsal Ağırlıklandırma (Simple Additive Weighting-SAW), TOPSIS, Karmaşı Nisbi Değerlendirme (COmplex PRopotional Assessment-COPRAS) vb. gibi yöntemlerdir (Abdel-Basset ve Mohamed, 2020: 3). Bu çalışmada da kriter ağırlık değerlerinin belirlenmesinde tercihlere dayalı olan AHP yöntemi ve hem tercihlere hem de matematiksel işlemlere dayalı olan MAIRCA yöntemi karar verme modeline dahil edilmiştir.

\subsection{Analitik hiyerarşi süreci}

AHP yöntemi Thomas L. Saaty tarafından 1971-1975 yılları arasından geliştirilmiştir (Saaty, 1987: 161). AHP yöntemi, dikkate alınan kriterlerdeki performansları ve bu kriterlerin önemini ölçmek için oran ölçeklerine dayanan bir ÇKKV yöntemidir (Abastante vd., 2019: 111). AHP yöntemi hem kesikli hem de sürekli ikili karş1laştırmalardan türetilen oran ölçekleri için kullanılır. İkili karşılaştırmalar, gerçek ölçümlerden veya tercihleri ve duyguları kıyaslanabilir şekilde yansıtan temel bir ölçekten alınabilir (Saaty ve Vargas, 2012: 3).

Yıllar itibariyle AHP yöntemi farklı küme teorileri ve birçok farklı yöntem ile ÇKKV problemlerinin çözümünde kullanılmıştır. Bu problemlere örnek olarak; üniversite (Saaty, 1987), ev ve personel (Saaty, 1990), depo yeri (Korpela ve Tuominen, 1996), market yeri (Kuo vd., 1999), personel (Cheng ve Li, 2001), yazilım (Lai vd., 2002), meslek (Saaty, 2008), öğrenci (Soba vd., 2016), şirket performans (Ömürbek ve Aksoy, 2016), yenilebilir enerji kaynağı (Algarin vd., 2017), yaşam kalitesi (Kara, 2019), enerji tasarrufu için en uygun iletişim aracı (Hilorme vd., 2019) ve yenilenebilir enerji için tesis yeri (Kutlu Gündoğdu ve Kahraman, 2020) seçimi/analizi çalışmaları örnek olarak gösterilebilir.

AHP yöntemi karmaşık problemleri basit ve kolay alt problemlere ayırarak hiyerarşik yapıda analiz eder (Abdel-Basset, Mohamed, Elhoseny ve Chang, 2020: 5). AHP yöntemi uygulama işlem basamakları (AbdelBaset, Ding, Mohamed ve Metava, 2020: 202);

Adım 1. Problem daha küçük alt problemlere bölünür.

Adım 2. Probleme ait hiyerarşik yapı oluşturulur. İlk seviyede ulaşılacak hedef, ara seviyelerde kriterler ve alt kriterler ve son seviyede ise alternatifler yer alır.

Adım 3. İkili karşılaştırmalar ile karar matrisi oluşturulur. Karar verici tercihlerine göre klasik, bulanık veya Neutrosophic ölçekler kullanılabilir.

Adım 4. Kriter ve alternatiflerin ikili karşılaştırmalarının ağırlıkları hesaplanır.

Karar matrisi (A) Denklem (9)'da gösterildiği gibi karşılaştırma yapılan kriterler veya alternatifler için oluşturulur. 


$$
A=\left(\begin{array}{cccc}
c_{1} / c_{1} & c_{1} / c_{2} & \ldots & c_{1} / c_{n} \\
c_{2} / c_{1} & c_{2} / c_{2} & \ldots & c_{2} / c_{n} \\
\vdots & \vdots & \ddots & \vdots \\
c_{n} / c_{1} & c_{n} / c_{2} & \ldots & c_{n} / c_{n}
\end{array}\right)=\left(\begin{array}{cccc}
a_{11} & a_{12} & \cdots & a_{1 n} \\
a_{21} & a_{22} & \cdots & a_{2 n} \\
\vdots & \vdots & \ddots & \vdots \\
a_{n 1} & a_{n 2} & \cdots & a_{n n}
\end{array}\right) ; i, j=1,2, \ldots, n
$$

Denklem (9)'da gösterildiği gibi $A$ matrisinin her elemanı $a_{i j}={ }^{c_{i}} / c_{j}$ olarak pozitif girdilere sahiptir ve elemanlar karşılıklı olarak $a_{i j}=1 / a_{j i}$ özelliğini karşılar. Bu özelliğe sahip herhangi bir matrise ikili karşılaştırmalar matrisi (reciprocal matrix) denir (Saaty, 1990: 12).

Kriterler veya alternatiflere ait karar matrisinden Denklem (10)'da gösterildiği gibi özvektör sütun matrisi değerleri $\left(w_{i}\right)$ elde edilir (Soba vd., 2016: 114).

$$
w_{i}=\frac{1}{n} \sum_{j=1}^{n} \frac{a_{i j}}{\sum_{i=1}^{n} a_{i j}} ; i, j=1,2, \ldots, n
$$

Denklem (10)'da gösterildiği gibi karar matrisi her elemanı sütun toplamlarına bölünür ve satır elemanlarının aritmetik ortalaması her kriter veya alternatife ait öncelik/ağırlık değerini verir.

Tutarlılık İndeksi'nin hesaplanmasında kullanılan maksimum özdeğer $\left(\lambda_{\max }\right)$ Denklem (11) kullanılarak elde edilir (Soba vd., 2016: 115).

$$
\lambda_{\max }=\frac{1}{n} \sum_{i=1}^{n} \frac{\sum_{j=1}^{n}\left(a_{i j} w_{i}\right)}{w_{i}}
$$

Denklem (11)'de de gösterildiği gibi ikili karşılaştırma matrisi elemanları sıralı olarak her sütun için özvektör sütun matrisinin bir satırına karşılık gelecek şekilde ağırlıklandırılır. Ağırlıklandırılmış matrisin her satır toplamı özvektör sütun matrisindeki karşılık gelen satır değerine bölünür ve bu değerlerin ortalaması özdeğeri $\left(\lambda_{\text {max }}\right)$ verir (Ömürbek ve Aksoy, 2016: 727).

Adım 5. Tutarlılık Oranı (Consistency Ratio-CR) hesaplanarak karar matrisini iyileştirmek için karar matrisi tutarlılı̆̆ı kontrol edilir. Tutarlılık Oranı Denklem (12)'de gösterildiği gibi hesaplanır.

$$
C R=\frac{C I}{R I}
$$

Tutarlılık İndeksi (Consistency Index-CI) özdeğerin kriter karşılığına bölümüdür ve n kriter/alternatif sayısı olmak üzere Denklem (13)'te gösterilmiştir.

$$
C I=\frac{\lambda_{\max }-n}{n-1}
$$

Rastgelelik İndeksi (Random Index-RI) ise doğrudan kriter sayısını dikkate alan bir fonksiyonun değerleridir. Kriter ve alternatif sayılarına göre Rastgelelik İndeks değerlerine Saaty ve Vargas (2012) tarafından yapılan çalışmadan erişilebilir. Eğer Tutarlılık İndeksi 0,10'dan büyükse problem tekrar incelenmeli ve karar verici yargıları gözden geçirilip düzeltilmelidir (Saaty ve Vargas, 2012: 9).

\section{2. Çok nitelikli ideal-gerçek karşılaştırma analizi}

Çok Nitelikli İdeal-Gerçek Karşılaştırma Analizi (Multi Attributive Ideal-Real Comparative AnalysisMAIRCA) yöntemi ilk olarak Belgrad'daki Savunma Üniversitesi Lojistik Araştırmalar Merkezi tarafindan önerilmiştir (Pamucar vd., 2014: 90; Gigovic vd., 2016: 11). MAIRCA yönteminin temel varsayımı, ideal ve ampirik ağırlıklar arasındaki boşluğu belirlemektir. Her kriter için boşlukların toplanması, gözlemlenen her alternatif için toplam boşluğu verir. Son olarak, alternatifler bu boşluk değerine göre sıralanır ve en iyi alternatif, toplam boşluğu en küçük olandır (Pamucar vd., 2017: 13).

Son yıllarda MAIRCA yöntemi: demiryolu hemzemin geçitleri için güvenlik ekipmanı seçim süreci (Pamucar vd., 2014), mühimmat depoları için yer seçimi (Gigovic vd., 2016), tedarikçi performansı değerlendirme (Chatterjee vd., 2018), catering firması seçimi (Ulutaş, 2019), tıbbi atık arıtma teknolojisi seçimi (Adar ve Delice, 2019), personel seçim süreci (Ayçin, 2020), işletmelerin finansal performans (Aydın, 2020; Ayçin ve Güçlü, 2020) ve etkinlik (Özdağoğlu vd., 2020) analizi gibi ÇKKV problemlerinin çözümünde kullanılmıştır.

MAIRCA yönteminin uygulama işlem basamakları (Pamucar vd., 2014: 91; Pamucar vd., 2018: Özçil vd., 2020: 736-737); 
Adım 1. Karar matrisi $(X)$ oluşturulur. Denklem (14)'teki $x_{i j}$, $i$. alternatife göre $j$. kriter özelliğini göstermektedir.

$$
X=\left[\begin{array}{ccc}
x_{11} & \cdots & x_{1 n} \\
\vdots & \ddots & \vdots \\
x_{m 1} & \cdots & x_{m n}
\end{array}\right] ; i=1,2, \ldots, m ; j=1,2, \ldots, n
$$

Karar matrisi elemanları ölçülebilir veya karşılaştırılabilir değerlerden oluşabilir. Ölçülebilir değerler kriterlerin gerçek göstergelerinden elde edilir. Karşılaştırılabilir değerler ise karar vericinin kişisel tercihleri veya uzman kararlarının birleştirilmesi ile elde edilir.

Adım 2. Alternatif seçimi için Tercih Katsayısı $\left(P_{A_{i}}\right)$ belirlenir. Karar verici seçim sürecindeki alternatiflere ve riske karşı tarafsızdır. Karar vericinin alternatif seçimlerinin tercih edilme olasılıklarını hesaba katmadığı varsayılmaktadır. Alternatiflerin her birinin eşit olasılıkla tercih edilmesi söz konusu olabilmektedir. Denklem (15)’te gösterildiği gibi Tercih Katsayısı alternatif sayısına göre belirlenir ve her alternatif için eşittir.

$$
P_{A_{i}}=\frac{1}{m} ; \sum_{i=1}^{m} P_{A_{i}}=1, i=1,2, \ldots, m
$$

Adım 3. Teorik Değerlendirme matrisi $\left(T_{p}\right)$ hesaplanır. Denklem (16)'da gösterilen Teorik Değerlendirme matrisi elemanları $\left(t_{p i j}\right)$ her alternatif için eşit olan Tercih Katsayısı $\left(P_{A_{i}}\right)$ ve kriter ağırlıklarının $\left(w_{j}, j=\right.$ $1,2, \ldots, n)$ çarpılması ile elde edilir. Kriter ağırlıkları, ağırlıklandırma yöntemleri veya karar verici tercihlerine göre belirlenebilir.

$$
T_{p}=\begin{gathered}
w_{1} \\
P_{A_{1}} \\
\vdots \\
P_{A_{m}}
\end{gathered}\left[\begin{array}{cccc}
t_{p 11}=P_{A_{1}} * w_{1} & \cdots & t_{p 1 n}=P_{A_{1}} * w_{n} \\
\vdots & \ddots & \vdots \\
t_{p m 1}=P_{A_{m}} * w_{1} & \cdots & t_{p m n}=P_{A_{m}} * w_{n}
\end{array}\right]
$$

Adım 4. Gerçek Değerlendirme matrisi $\left(T_{r}\right)$ oluşturulur. Denklem (17)'de gösterilen Gerçek Değerlendirme matrisi elemanları $\left(t_{r i j}\right)$, Teorik değerlendirme matrisi elemanları ile karar matrisinin normalize edilmiş değerlerinin çarpımından elde edilir.

$$
T_{r}=\begin{array}{ccc}
C_{1} & \cdots & C_{n} \\
A_{1} & \vdots \\
A_{m}
\end{array}\left[\begin{array}{ccc}
t_{r 11} & \cdots & t_{r 1 n} \\
\vdots & \ddots & \vdots \\
t_{r m 1} & \cdots & t_{r m n}
\end{array}\right]
$$

Karar matrisi elemanları normalize edilirken kriter türleri dikkate alınır. Daha büyük değerlerin tercih edildiği fayda kriterleri için Denklem (18) ve daha küçük değerlerin tercih edildiği maliyet kriterleri için de Denklem (19) kullanilır.

$$
\begin{aligned}
& t_{r i j}=t_{p i j}\left(\frac{x_{i j}-x_{i}^{-}}{x_{i}^{+}-x_{i}^{-}}\right) \\
& t_{r i j}=t_{p i j}\left(\frac{x_{i j}-x_{i}^{+}}{x_{i}^{-}-x_{i}^{+}}\right)
\end{aligned}
$$

Denklem (18) ve (19)'da gösterilen $x_{i j}$, karar matrisi elemanları; $x_{i}^{+}\left[\max \left(x_{i 1}, x_{i 2}, \ldots, x_{i m}\right), i=1,2, \ldots, n\right]$, her kriter için karar matrisi elemanlarının maksimum değeri ve $x_{i}^{-}\left[\min \left(x_{i 1}, x_{i 2}, \ldots, x_{i m}\right), i=1,2, \ldots, n\right]$, her kriter için karar matrisi elemanlarının minimum değeridir.

Adım 5. Toplam Boşluk matrisi $(G)$ hesaplanır. Teorik $\left(t_{p i j}\right)$ ve Gerçek $\left(t_{r i j}\right)$ Değerlendirme matrisi elemanları arasındaki farka göre Denklem (20)'de gösterilen Toplam Boşluk matrisi elemanları $\left(g_{i j}\right)$ bulunur.

$$
G=T_{p}-T_{r}=\left[\begin{array}{ccc}
g_{11} & \cdots & g_{1 n} \\
\vdots & \ddots & \vdots \\
g_{m 1} & \cdots & g_{m n}
\end{array}\right]
$$

Toplam boşluk matrisi elemanlarının $\left[0,\left(t_{p i j}-t_{r i j}\right)\right]$ aralığında alabileceği değerler Denklem (21)'de gösterilmiştir.

$$
g_{i j}=\left\{\begin{array}{cl}
0 & E \breve{\mathrm{g}} e r t_{p i j}=t_{r i j} \\
t_{p i j}-t_{r i j} & \text { Ĕg er } t_{p i j}>t_{r i j}
\end{array}\right.
$$


Teorik ve Gerçek Değerlendirme matrisleri elemanlarının eşitliği $\left(t_{p i j}=t_{r i j}\right)$ arzu edilen, hedeflenen durumdur. Eğer arada boşluk varsa $\left(t_{p i j}>t_{r i j}\right)$, bu ideal alternatiften uzaklığı göstermektedir.

Adım 6. Alternatifler için kriter fonksiyonlarının son değeri $\left(\mathcal{Q}_{i}\right)$ hesaplanır. Denklem (22)'de gösterilen kriter fonksiyonları son değerine göre alternatifler küçükten büyüğe doğru sıralanır. En düşük kriter fonksiyonları son değerine sahip olan alternatif en iyi alternatiftir.

$$
\mathcal{Q}_{i}=\sum_{j=1}^{n} g_{i j}, i=1,2, \ldots, m
$$

Adım 7. En iyi alternatife göre Baskınlık İndeksi $\left(A_{D, 1-i}\right)$ ve alternatiflerin nihai sıralamaları belirlenir. Baskınlık İndeksi hesaplanmadan önce Denklem (23)’te gösterilen $m$ alternatif sayısı olmak üzere Baskınlık Eşik Değeri $\left(I_{D}\right)$ hesaplanır.

$$
I_{D}=\frac{m-1}{m^{2}}
$$

En iyi alternatife göre Baskınlık İndeksi, diğer alternatiflerle olan ilişkinin avantajını tanımlar ve Eşitlik (24)’ün uygulanması ile belirlenir.

$$
A_{D, 1-i}=\left|\frac{\left|Q_{i}\right|-\left|Q_{1}\right|}{\left|Q_{n}\right|}\right|, i=1,2, \ldots, m
$$

Denklem (24)'teki $\mathcal{Q}_{1}$, en iyi sıradaki alternatifin kriter fonksiyonu son değerini; $\mathcal{Q}_{n}$, son sıradaki alternatifin kriter fonksiyonu son değerini ve $\mathcal{Q}_{i}, i$. alternatifin en iyi alternatifle karşılaştırılan kriter fonksiyonu değerini göstermektedir.

Baskınlık İndeksi'nin, Baskınlık Eşik Değeri’ne eşit veya büyük olması koşuluyla $\left(A_{D, 1-i} \geq I_{D}\right)$ elde edilen sıralama korunacaktır. Ancak Baskınlık İndeksi, Baskınlık Eşik Değeri'nden küçük $\left(A_{D, 1-i}<I_{D}\right)$ ise ilk sıradaki alternatifin analiz edilen alternatife göre bir avantaja sahip olduğu kesin olarak söylenemez. Söz konusu kisıtlamalar Denklem (25) uygulanarak gösterilebilir.

$$
R_{\text {Nihai }, i}=\left\{\begin{array}{lll}
A_{D, 1-i} \geq I_{D} & \Rightarrow & R_{\text {Nihai }, i}=R_{\dot{\mathrm{l}} l k, i} \\
A_{D, 1-i}<I_{D} & \Rightarrow & R_{\text {Nihai }, i}=R_{\mathrm{I} l k, 1}
\end{array}\right.
$$

Denklem (25)'teki $R_{\mathrm{I} l k, i}$ ve $R_{N i h a i, i}$ en iyi alternatifle karşılaştırılan alternatifin ilk ve nihai sıralamasını göstermektedir.

Eğer Baskınlık İndeksi’nin, Baskınlık Eşik Değeri’nden küçük olması koşulu sağlanırsa, en iyi dereceli alternatifle karşılaştırılan alternatifin sıralaması düzeltilecek ve " 1 *" değeri atanarak en iyi dereceli alternatif olarak değerlendirilecektir. Bu şekilde, en iyi sıralanan alternatifin, Baskınlık Eşik Değeri’nden daha küçük bir avantajla karakterize edildiği vurgulanmaktadır.

Örneğin en iyi sıralamaya sahip alternatif ile ikinci sıradaki alternatifin karşılaştırıldığı ve Baskınlık İndeksi’nin, Baskınlık Eşik Değeri'nden küçük olduğu $\left(A_{D, 1-2}<I_{D}\right)$ varsayılsın. Bu durumda ikinci sıradaki alternatife nihai sıralama için " 1 *” değeri atanacaktır. Karşılaştırma üçüncü sıradaki alternatifle devam edebilir. Üçüncü sıradaki alternatif için de Baskınlık İndeksi, Baskınlık Eşik Değeri’nden küçük $\left(A_{D, 1-3}<I_{D}\right)$ ise üçüncü sıradaki alternatife de " $1 * *$ " değeri atanacaktır ve bu, son alternatife ulaşılıncaya kadar devam edecektir.

Baskınlık İndeksi’nin, Baskınlık Eşik Değeri’nden küçük olduğu $\left(A_{D, 1-2}<I_{D}\right)$ durumlar için tüm alternatiflerin ilk sıralamalarının $\left(R_{\dot{I} l k}\right)$ düzeltilmesi gerçekleşirken Baskınlık İndeksi’nin, Baskınlık Eşik Değeri’ne eşit veya büyük olduğu $\left(A_{D, 1-2} \geq I_{D}\right)$ durumlar için alternatiflerin sıralamaları değişmeden kalır. Böylece alternatiflerin nihai sıralaması $\left(R_{\text {Nihai }}\right)$ ile eşzamanlı olarak sunulan alternatiflerin ilk sıralaması $\left(R_{\dot{\mathrm{I} l k}}\right)$ elde edilir.

\section{Uygulama}

Gerçek hayatta, Karar Verici’ler (KV'ler) karmaşıklık ve insan bilişinin belirsizliği nedeniyle klasik küme sayılarını kullanmak yerine dilsel terimleri kullanma eğilimindedir (Grida vd., 2020: 3). Dergi seçim sürecindeki bir araştırmacının da alternatifleri değerlendirirken dilsel değişkenler kullanması ve Plithogenic küme teorisinden faydalanması gerçek hayattaki belirsizlik içeren niteliklere daha uygun karar vermesini sağlayacaktır. Bu nedenle ÇKKV problemi olarak dergi seçim süreci ilk defa Plithogenic küme teorisi ile birlikte ele alınmıştır. Uygulama modelinin genel süreç işlem basamağı Şekil 1'de verilmiştir. 
Şekil 1. Dergi seçim süreci

\begin{tabular}{|c|c|c|c|}
\hline $\begin{array}{c}\text { Yayınlanacak Çalışmanın } \\
\text { Tamamlanması }\end{array}$ & Dergi Seçim Problemi & \multicolumn{2}{|c|}{ Kriterlerin Belirlenmesi } \\
\hline Alternatiflerin Belirlenmesi & $\begin{array}{l}\text { Kriter Ağırlıklarının } \\
\text { Hesablanması }\end{array}$ & \multicolumn{2}{|c|}{$\begin{array}{c}\text { Kriterlerin Plithogenic } \\
\text { Küme ile Karsılastırılması }\end{array}$} \\
\hline $\begin{array}{l}\text { Sübjektif Kriterler için Alter } \\
\text { Plithogenic Küme ile Karşıl }\end{array}$ & \multicolumn{2}{|c|}{$\begin{array}{c}\text { Objektif ve Sübjektif Kriterler ile Alter- } \\
\text { natiflerin Stralanması }\end{array}$} & $\begin{array}{l}\text { Dergi Seçim } \\
\quad \text { Kararı }\end{array}$ \\
\hline
\end{tabular}

Giriş bölümünde verilen dergi seçim süreci ile ilgili literatürde yer alan çalışmaların incelenmesi sonucu kriter olarak;

- Sübjektif Kriterler $\left(\mathrm{G}_{1}\right)$; İçerik Uyumu $\left(C_{1}\right)$, Hakem Kurulu $\left(C_{2}\right)$ ve Teknik Düzenleme $\left(C_{3}\right)$,

- Dergi Göstergeleri $\left(\mathrm{G}_{2}\right)$; Alıntı Skoru $\left(C_{4}\right)$, Etki Faktörü $\left(C_{5}\right)$, Kabul Oranı $\left(C_{6}\right)$ ve Yayın Süresi $\left(C_{7}\right)$,

- Diğer Göstergeler $\left(\mathrm{G}_{3}\right)$; Yı1lık Yayın Sayısı $\left(C_{8}\right)$, Teşvik Miktarı $\left(C_{9}\right)$ ve Dergi Fiyatı $\left(C_{10}\right)$ olarak belirlenmiştir.

Üç $\mathrm{KV}\left(\mathrm{KV}_{1}, \mathrm{KV}_{2}\right.$ ve $\left.\mathrm{KV}_{3}\right)$ tarafindan kriterler, ağırlık değerlerinin bulunması amacıyla Tablo 1'de gösterilen dilsel değişkenler kullanılarak karşılaştırılmıştır. KV'lerin ortak bir makale çalışması için dergi seçim kararı vereceği varsayılmıştır.

Tablo 1. Dilsel ifadeler ve Plithogenic sayı karşılıkları (*)

\begin{tabular}{lcc}
\hline Dilsel ifade ile önem/etki seviyesi (kısaltma) & Plithogenic sayı (T, I, F) & Skor indeksi \\
\hline Kesinlikle çok önemli (KÇ) & $(0,9,0,1,0,0)$ & 9 \\
\hline Çok fazla önemli (ÇF) & $(0,8,0,2,0,1)$ & 7 \\
\hline Çok önemli (Ç) & $(0,7,0,3,0,2)$ & 5 \\
\hline Biraz fazla önemli (BF) & $(0,6,0,4,0,3)$ & 3 \\
\hline Eşit derecede önemli (E) & $(0,5,0,4,0,4)$ & 1 \\
\hline Biraz az derecede önemli (BA) & $(0,4,0,6,0,3)$ & $1 / 3$ \\
\hline Düşük derecede önemli (D) & $(0,3,0,7,0,2)$ & $1 / 7$ \\
\hline Çok düşük derecede önemli (ÇD) & $(0,2,0,8,0,1)$ & $1 / 9$ \\
\hline Kesinlikle az seviyede önemli (KA) & $(0,1,0,9,0,0)$ & \\
\hline
\end{tabular}

$(*)$ Kaynak: Kutlu Gündoğdu ve Kahraman, 2020: 4614.

Kriterler karşılaştırılırken, içerik uyumu kriteri için derginin amaç ve kapsamları KV'ler tarafindan okunmuştur ve çalışmanın içeriği ile karşılaştırılmıştır. Çalışmanın içeriği ile uyumluluk derecesi olarak değerlendirilmiş̧ir. Hakem kurulu kriteri için derginin hakem ve editör kurulları incelenerek KV'ler tarafindan hem ilgili alana uygunluk hem de ülkeler arası dağılım ve toplam hakem sayıları değerlendirilmiştir. Teknik düzenleme kriteri için KV’lerin dergiye makale gönderimi öncesinde çalışmaları ile ilgili yaptığı hazırlıklar göz önünde bulundurulmuştur. Derginin hangi formatta çalışma kabul ettiği (Word/Latex), bu formatlara uygun örneklerin olup olmadığı, örnek makale çalışmalarının ücretsiz sunulup sunulmadığı, sayfa sınırı ve kaynakça düzenleme şekli (Mendeley, Bibtex, Word) ile ilgili özellikleri KV’ler tarafından değerlendirilmiştir.

Objektif verilerin elde edildiği diğer kriterlerden alıntı skoru, etki faktörü ve kabul oranı kriterleri dergilerin sayfalarından edinilen bilgiler ile oluşturulmuştur. Dergilerin yayın süreleri incelendiğinde ortalama ilk karar ve yayınlanma süresi arasında farklılık olduğu görülmüsstür. İlk karar süresi kısa olduğu durumlarda yayınlanma süresinin uzun bir zaman alabildiği veya tam tersi durumların da olduğu görülmüştür. Bu nedenle yayın süresi kriteri dergilerin ortalama ilk karar ve yayınlanma süresi bilgileri toplanarak elde edilmiştir. Dergilerin yılllk yayın sıklıkları incelendiğinde hem dergilerin kendi sayıları arasında hem de diğer dergilere kıyasla farklı sayıda makaleler yayınlanmaktadır. Bu nedenle dergilerin 2020 yılına ait tüm sayılarında yayınladıkları çalışmalar yıllık yayın sayısı kriteri olarak dikkate alınmıştır. Teşvik miktarı kriteri ise TÜBİTAK tarafından Uluslararası Bilimsel Yayınları Teşvik (UBYT) Programı kapsamında, 2020 yılı için araştırmacılara sağlanan mali destek miktarına göre belirlenmiştir (TÜBİTAK, 2021). Dergi fiyatı (\$) kriteri ise dergilerin 2020 yılına ait son sayıdaki makale erişim ücretleri baz alınarak oluşturulmuştur. Yayın süresi ve dergi fiyatı kriterleri maliyet yönlüdür, diğer kriterler ise fayda yönlü olarak belirlenmiştir.

KV'ler alternatif dergi seçeneklerini belirlerken SCI, SCI-E (Science Citation Index-Expanded) ve/veya SSCI (Social Sciences Citation Index) dizinlerinde yer alan bir dergide çalışmalarını yayınlatmak istediği ve 
yayıncı olarak Elsevier'i seçtiği varsayılmıştır. Ayrıca alternatifler belirlenirken Telif hakkının devredildiği, kör hakemlik uygulamasına sahip ve değerlendirme/yayın ücreti olmayan dergiler tercih edilmiştir. Yayıncının sunduğu özet eşleşme (Abstract Finder) hizmeti ile belirlenen dokuz alternatif ve on kritere ait dergi seçim sürecinin AHP yöntemine uygun hiyerarşik yapısı Şekil 2'de gösterilmiştir.

Şekil 2. Problemin hiyerarşik yapısı

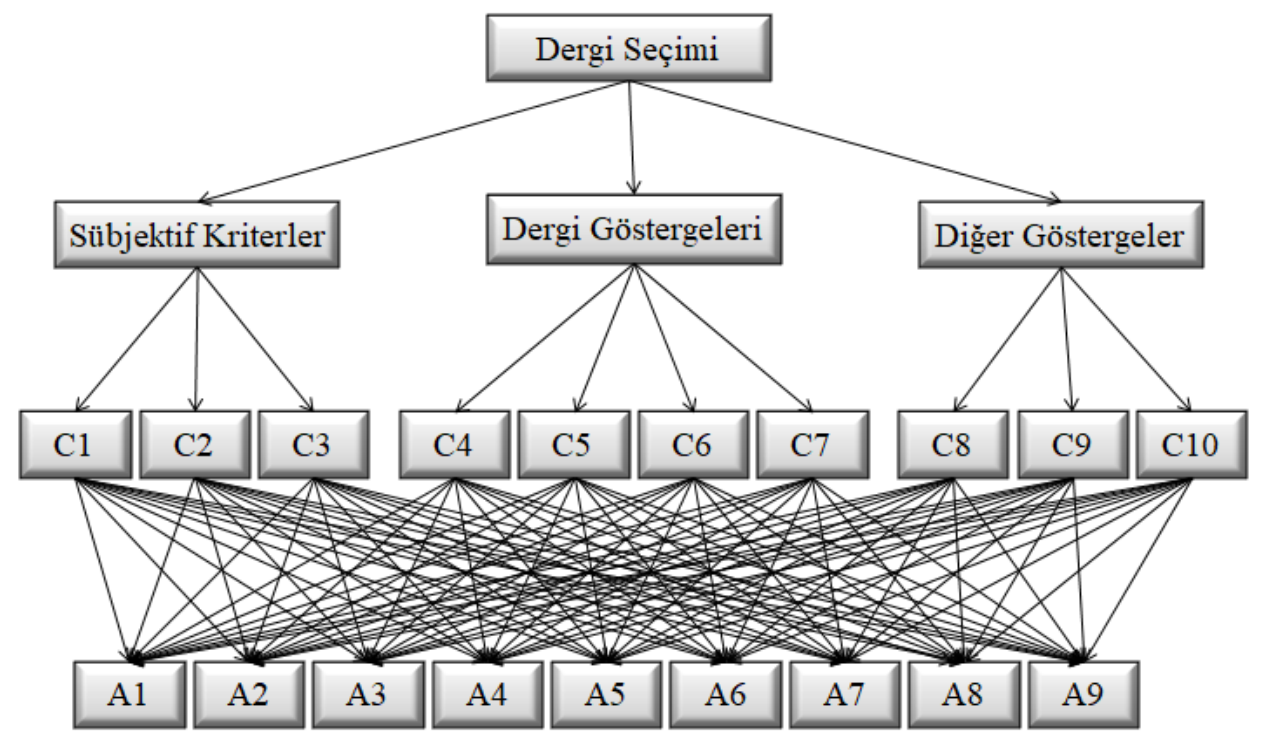

Dergi seçim süreci karar verme problemi yapısı kriter ve alternatifler ile oluşturulduktan sonra kriterlerin ağırlık değerlerinin belirlenmesi amacıyla KV'ler tarafından kriterler Tablo 1'de gösterilen dilsel değişkenlerle ikili olarak karşılaştırılmıştır.

\subsection{Plithogenic birleştirme operatörü}

Plithogenic birleştirme operatörü kullanımı hem kriterlerin ağırlık değerlerinin belirlenmesinde hem de sübjektif kriterler açısından alternatiflerin karşılaştırılmasında kullanılmıştır. Belirlenen kriterlerin hiyerarşik yapısından dolayı Sübjektif $\left(\mathrm{G}_{1}\right)$, Dergi Göstergeleri $\left(\mathrm{G}_{2}\right)$ ve Diğer Göstergeler $\left(\mathrm{G}_{3}\right)$ olarak belirtilen temel kriterler kendi arasında ve alt kriterleri de yine kendi arasında ikili olarak karşılaştırılmıştır. Temel kriterlerin Tablo 1'de gösterilen dilsel değişkenler kullanılarak yapılan karşılaştırmalarına ve Plithogenic küme gereği KV'ler tarafından fikir birliği ile belirlenen Çelişki Dereceleri'ne (c) Tablo 2'de yer verilmiştir.

Tablo 2. Temel kriterler için ikili karşılaştırmalar

\begin{tabular}{|c|c|c|c|c|c|}
\hline \multirow{2}{*}{$\mathrm{KV}$} & \multirow{2}{*}{ Kriter } & \multicolumn{3}{|c|}{ İkili karşılaştırmalar } & \multirow{2}{*}{ Çelişki derecesi } \\
\hline & & $\mathrm{G}_{1}$ & $\mathrm{G}_{2}$ & $\mathrm{G}_{3}$ & \\
\hline \multirow{3}{*}{$\mathrm{KV}_{1}$} & $\mathrm{G}_{1}$ & $\mathrm{E}$ & $\mathrm{E}$ & KD & 0,50 \\
\hline & $\mathrm{G}_{2}$ & $\mathrm{E}$ & $\mathrm{E}$ & Ç & 0,00 \\
\hline & $\mathrm{G}_{3}$ & KA & $\mathrm{D}$ & $\mathrm{E}$ & 0,25 \\
\hline \multirow{3}{*}{$\mathrm{KV}_{2}$} & $\mathrm{G}_{1}$ & $\mathrm{E}$ & ÇF & KD & 0,50 \\
\hline & $\mathrm{G}_{2}$ & ÇD & $\mathrm{E}$ & $\mathrm{E}$ & 0,00 \\
\hline & $\mathrm{G}_{3}$ & KA & $\mathrm{E}$ & $\mathrm{E}$ & 0,25 \\
\hline \multirow{3}{*}{$\mathrm{KV}_{3}$} & $\mathrm{G}_{1}$ & $\mathrm{E}$ & $\mathrm{BF}$ & KD & 0,50 \\
\hline & $\mathrm{G}_{2}$ & $\mathrm{BA}$ & $\mathrm{E}$ & Ç & 0,00 \\
\hline & $\mathrm{G}_{3}$ & KA & $\mathrm{D}$ & $\mathrm{E}$ & 0,25 \\
\hline
\end{tabular}

Ayrıca Tablo 1'de gösterilen skor puanları kullanılarak Tablo 2'deki ikili karşılaştırmaların her KV için Eşitlik (9-13) yardımıyla Tutarlılık Oranı değerleri sırasıyla 0,033, 0,006 ve 0,025 olarak hesaplanmıştır. Dolayısıyla bu değerler 0,10 sınır değerinin altında olduğu için karşılaştırmaların tutarlı olduğu sonucuna varılmıştır. Tablo 2'de gösterilen dilsel değişkenlerin Tablo 1'de gösterilen Neutrosophic sayılar ve Çelişki Dereceleri kullanılarak Denklem (6) yardımıyla hesaplanan birleştirilmiş KV karşılaştırmalarına $\left[\left(\widetilde{K V}_{1} \wedge_{P} \widetilde{K V}_{2}\right) \wedge_{P} \widetilde{K V}_{3}\right]$ Tablo 3 'te yer verilmiştir.

Tablo 3. Temel kriterlerin birleștirilmiș Plithogenic değerleri

\begin{tabular}{cccc}
\hline & $\mathrm{G}_{1}(\mathrm{~T}, \mathrm{I}, \mathrm{F})$ & $\mathrm{G}_{2}(\mathrm{~T}, \mathrm{I}, \mathrm{F})$ & $\mathrm{G}_{3}(\mathrm{~T}, \mathrm{I}, \mathrm{F})$ \\
\hline $\mathrm{G}_{1}$ & $(0,500,0,400,0,400)$ & $(0,240,0,350,0,622)$ & $(0,824,0,100,0,000)$ \\
\hline $\mathrm{G}_{2}$ & $(0,375,0,600,0,275)$ & $(0,125,0,400,0,784)$ & $(0,460,0,325,0,417)$ \\
\hline $\mathrm{G}_{3}$ & $(0,100,0,900,0,000)$ & $(0,045,0,625,0,616)$ & $(0,313,0,400,0,586)$ \\
\hline
\end{tabular}


Tablo 3’te gösterilen birleştirilmiş değerler hesaplanırken KV karşılaştırmaları Çelişki Derecesi ve Eşitlik (46) yardımıyla birleştirilmiştir. KV'lerin alt kriterler için yaptığı ikili karşılaştırmalara ve hesaplanan birleştirilmiş Plithogenic değerlere Ekler kısmında Tablo 11-16 olarak yer verilmiştir. Ayrıca alternatifler Tablo 1'de gösterilen dilsel değişkenler ile sübjektif kriterler için de karşılaştırılmıştır. Bu karşılaştırmalara ve Plithogenic değer sonuçlarına da Ekler kısmında Tablo 17 ve 18 olarak yer verilmiştir. Birleştirilmiş Plithogenic değerlerin Eşitlik (8) yardımıyla klasik küme değerleri hesaplanmıştır. Bu değerler MAIRCA yöntemi için karar matrisi değerlerini oluşturmaktadır.

\section{2. $A H P$}

Birleştirilmiş KV değerlendirmelerinin yer aldığı Tablo 3'te gösterilen değerler Eşitlik (8) kullanılarak klasik küme değerlerine dönüştürülmüştür. Tablo 4'te gösterilen bu değerler AHP yönteminde temel kriterlerin ağırlık değerlerinin hesaplanmasında kullanılmıştır.

Tablo 4. Temel kriterler için AHP yöntemi karar matrisi

\begin{tabular}{cccc}
\hline & $\mathrm{G}_{1}$ & $\mathrm{G}_{2}$ & $\mathrm{G}_{3}$ \\
\hline $\mathrm{G}_{1}$ & 0,560 & 0,377 & 0,909 \\
\hline $\mathrm{G}_{2}$ & 0,520 & 0,256 & 0,552 \\
\hline $\mathrm{G}_{3}$ & 0,460 & 0,247 & 0,411 \\
\hline
\end{tabular}

Temel kriterler için Tablo 4’te gösterilen AHP yöntemi karar matrisi Eşitlik (10)'da gösterildiği gibi sütun toplamları ile normalize edilmiştir ve satır ortalamaları alınarak ağırlık değerleri bulunmuştur. Aynı işlemler ekler kısmında bilgileri verilen alt kriterler için de tekrar edilmiştir ve kriterlerin yerel ve global ağırlık değerleri Tablo 5'te gösterilmiştir.

Tablo 5. Tüm kriterler için yerel ve global ağırlık değerleri

\begin{tabular}{|c|c|c|c|c|c|c|c|c|c|c|}
\hline Temel Kriter & \multicolumn{3}{|c|}{$\mathrm{G}_{1}$} & \multicolumn{4}{|c|}{$\mathrm{G}_{2}$} & \multicolumn{3}{|c|}{$\mathrm{G}_{3}$} \\
\hline Ağırlık Değeri & & 0,426 & & & & & & & 0,266 & \\
\hline Alt Kriter & $\mathrm{C}_{1}$ & $\mathrm{C}_{2}$ & $\mathrm{C}_{3}$ & $\mathrm{C}_{4}$ & $\mathrm{C}_{5}$ & $\mathrm{C}_{6}$ & $\mathrm{C}_{7}$ & $\mathrm{C}_{8}$ & $\mathrm{C}_{9}$ & $\mathrm{C}_{10}$ \\
\hline Yerel Ağırlık & 0,355 & 0,321 & 0,325 & 0,286 & 0,335 & 0,379 & 0,315 & 0,361 & 0,309 & 0,330 \\
\hline Global Ağırlık & 0,151 & 0,137 & 0,138 & 0,088 & 0,103 & 0,117 & 0,097 & 0,096 & 0,082 & 0,088 \\
\hline
\end{tabular}

İkili karşılaştırmalara ait tutarlılık dereceleri Ekler kısmında gösterilen tablolarda verilmiştir. Herhangi bir tutarlılık derecesinin 0,10'dan büyük olmadığı ve tutarlılık şartının sağlandığı görülmüştür. Kriterlerin global ağırlıkları incelendiğinde $K V^{\prime}$ 'ler tarafından en fazla önem verilen kriterler sırasıyla $C_{1}, C_{3}$ ve $C_{2}$ olarak, en az önem verilen kriterler ise sırasıyla $\mathrm{C}_{9}, \mathrm{C}_{4}$ ve $\mathrm{C}_{10}$ olarak belirlenmiştir.

\subsection{MAIRCA}

KV'ler tarafından alternatifler belirlenen sübjektif kriterlere göre dilsel değişkenlerle karşılaştırılmıştır ve bu karşılaştırmaların Plithogenic operatörler ile birleştirme işlemi yapılmıştır. Bu karşılaştırmaların birleştirilmesinde KV'lerin akademik tecrübelerine, yayın sayılarına ve kişisel özelliklerine göre Çelişki Dereceleri ortak fikir birliği ile belirlenmiştir. Ekler kısmında alternatiflerin sübjektif kriterler için ikili karşılaştırmalarına ve Plithogenic değerlerine Tablo 17 ve 18 olarak yer verilmiştir. Bu Plithogenic değerlerin Eşitlik (8) yardımıyla klasik küme değerlerine dönüştürülmesi sonucu elde edilen karar matrisi Tablo 6'da gösterilmiştir.

Tablo 6. MAIRCA yöntemi için karar matrisi

\begin{tabular}{ccccccccccc}
\hline \multirow{2}{*}{ Alternatifler } & \multicolumn{10}{c}{ Kriterler } \\
\cline { 2 - 12 } & $\mathrm{C}_{1}$ & $\mathrm{C}_{2}$ & $\mathrm{C}_{3}$ & $\mathrm{C}_{4}$ & $\mathrm{C}_{5}$ & $\mathrm{C}_{6}$ & $\mathrm{C}_{7}$ & $\mathrm{C}_{8}$ & $\mathrm{C}_{9}$ & $\mathrm{C}_{10}$ \\
\hline $\mathrm{A}_{1}$ & 0,310 & 0,399 & 0,448 & 4,4 & 4,149 & 0,16 & 41 & 139 & 2275 & 35,95 \\
\hline $\mathrm{A}_{2}$ & 0,325 & 0,381 & 0,415 & 11,7 & 5,921 & 0,21 & 14 & 723 & 4970 & 24,95 \\
\hline $\mathrm{A}_{3}$ & 0,471 & 0,403 & 0,403 & 10,9 & 5,324 & 0,10 & 55 & 142 & 6955 & 39,95 \\
\hline $\mathrm{A}_{4}$ & 0,383 & 0,676 & 0,561 & 11,3 & 5,910 & 0,20 & 11 & 919 & 5555 & 37,95 \\
\hline $\mathrm{A}_{5}$ & 0,246 & 0,388 & 0,842 & 9,5 & 4,271 & 0,06 & 9 & 115 & 5070 & 39,95 \\
\hline $\mathrm{A}_{6}$ & 0,240 & 0,734 & 0,656 & 8,5 & 4,213 & 0,17 & 25 & 637 & 5280 & 35,95 \\
\hline $\mathrm{A}_{7}$ & 0,645 & 0,584 & 0,501 & 8,6 & 4,787 & 0,11 & 15 & 247 & 3130 & 35,95 \\
\hline $\mathrm{A}_{8}$ & 0,259 & 0,433 & 0,404 & 7,5 & 5,268 & 0,13 & 8 & 705 & 2900 & 31,50 \\
\hline $\mathrm{A}_{9}$ & 0,471 & 0,842 & 0,383 & 6,5 & 4,105 & 0,14 & 9 & 439 & 3790 & 39,95 \\
\hline
\end{tabular}

MAIRCA yöntemi için karar matrisi oluşturulduktan sonra Eşitlik (15)’te gösterildiği gibi alternatif sayısı dokuz olduğu için her alternatifin Tercih Katsayısı 1/9 olarak belirlenmiştir. Tercih Katsayısı ve Tablo 5'te gösterilen kriterlerin global ağırlık değerleri kullanılarak Teorik Değerlendirme matrisi Tablo 7'de gösterildiği gibi hesaplanmıştır. 
Tablo 7. MAIRCA yöntemi için teorik değerlendirme matrisi

\begin{tabular}{ccccccccccc}
\hline $\mathrm{T}(\mathrm{p})$ & \multicolumn{10}{c}{ Kriterler } \\
\hline Alternatifler & $\mathrm{C}_{1}$ & $\mathrm{C}_{2}$ & $\mathrm{C}_{3}$ & $\mathrm{C}_{4}$ & $\mathrm{C}_{5}$ & $\mathrm{C}_{6}$ & $\mathrm{C}_{7}$ & $\mathrm{C}_{8}$ & $\mathrm{C}_{9}$ & $\mathrm{C}_{10}$ \\
\hline $\mathrm{A}_{1}$ & 0,017 & 0,015 & 0,015 & 0,010 & 0,011 & 0,013 & 0,011 & 0,011 & 0,009 & 0,010 \\
\hline $\mathrm{A}_{2}$ & 0,017 & 0,015 & 0,015 & 0,010 & 0,011 & 0,013 & 0,011 & 0,011 & 0,009 & 0,010 \\
\hline $\mathrm{A}_{3}$ & 0,017 & 0,015 & 0,015 & 0,010 & 0,011 & 0,013 & 0,011 & 0,011 & 0,009 & 0,010 \\
\hline $\mathrm{A}_{4}$ & 0,017 & 0,015 & 0,015 & 0,010 & 0,011 & 0,013 & 0,011 & 0,011 & 0,009 & 0,010 \\
\hline $\mathrm{A}_{5}$ & 0,017 & 0,015 & 0,015 & 0,010 & 0,011 & 0,013 & 0,011 & 0,011 & 0,009 & 0,010 \\
\hline $\mathrm{A}_{6}$ & 0,017 & 0,015 & 0,015 & 0,010 & 0,011 & 0,013 & 0,011 & 0,011 & 0,009 & 0,010 \\
\hline $\mathrm{A}_{7}$ & 0,017 & 0,015 & 0,015 & 0,010 & 0,011 & 0,013 & 0,011 & 0,011 & 0,009 & 0,010 \\
\hline $\mathrm{A}_{8}$ & 0,017 & 0,015 & 0,015 & 0,010 & 0,011 & 0,013 & 0,011 & 0,011 & 0,009 & 0,010 \\
\hline $\mathrm{A}_{9}$ & 0,017 & 0,015 & 0,015 & 0,010 & 0,011 & 0,013 & 0,011 & 0,011 & 0,009 & 0,010 \\
\hline
\end{tabular}

Teorik değerlendirme matrisi oluşturulduktan sonra karar matrisi Eşitlik (18) ve (19) kullanılarak normalize edilmiştir. Kriterlerden sadece $\mathrm{C}_{7}$ ve $\mathrm{C}_{10}$ kriterleri maliyet yönlü olarak dikkate alınmıştır. Normalize edilmiş karar matrisi değerlerinin Teorik Değerlendirme matrisi elemanları ile çarpımı sonucunda Gerçek Değerlendirme matrisi elde edilmiştir ve Tablo 8'de gösterilmiştir.

Tablo 8. MAIRCA yöntemi için gerçek değerlendirme matrisi

\begin{tabular}{ccccccccccc}
\hline $\mathrm{T}(\mathrm{r})$ & \multicolumn{10}{c}{ Kriterler } \\
\hline Alternatifler & $\mathrm{C}_{1}$ & $\mathrm{C}_{2}$ & $\mathrm{C}_{3}$ & $\mathrm{C}_{4}$ & $\mathrm{C}_{5}$ & $\mathrm{C}_{6}$ & $\mathrm{C}_{7}$ & $\mathrm{C}_{8}$ & $\mathrm{C}_{9}$ & $\mathrm{C}_{10}$ \\
\hline $\mathrm{A}_{1}$ & 0,0029 & 0,0006 & 0,0022 & 0,0000 & 0,0003 & 0,0086 & 0,0032 & 0,0003 & 0,0000 & 0,0026 \\
\hline $\mathrm{A}_{2}$ & 0,0036 & 0,0000 & 0,0011 & 0,0098 & 0,0115 & 0,0130 & 0,0094 & 0,0081 & 0,0053 & 0,0097 \\
\hline $\mathrm{A}_{3}$ & 0,0096 & 0,0007 & 0,0007 & 0,0087 & 0,0077 & 0,0035 & 0,0000 & 0,0004 & 0,0091 & 0,0000 \\
\hline $\mathrm{A}_{4}$ & 0,0059 & 0,0097 & 0,0060 & 0,0093 & 0,0114 & 0,0121 & 0,0101 & 0,0107 & 0,0064 & 0,0013 \\
\hline $\mathrm{A}_{5}$ & 0,0003 & 0,0002 & 0,0154 & 0,0068 & 0,0010 & 0,0000 & 0,0105 & 0,0000 & 0,0055 & 0,0000 \\
\hline $\mathrm{A}_{6}$ & 0,0000 & 0,0116 & 0,0091 & 0,0055 & 0,0007 & 0,0095 & 0,0069 & 0,0069 & 0,0059 & 0,0026 \\
\hline $\mathrm{A}_{7}$ & 0,0168 & 0,0067 & 0,0040 & 0,0056 & 0,0043 & 0,0043 & 0,0092 & 0,0018 & 0,0017 & 0,0026 \\
\hline $\mathrm{A}_{8}$ & 0,0008 & 0,0017 & 0,0007 & 0,0042 & 0,0073 & 0,0060 & 0,0108 & 0,0078 & 0,0012 & 0,0055 \\
\hline $\mathrm{A}_{9}$ & 0,0096 & 0,0152 & 0,0000 & 0,0028 & 0,0000 & 0,0069 & 0,0105 & 0,0043 & 0,0030 & 0,0000 \\
\hline
\end{tabular}

Teorik ve Gerçek değerlendirme matrisi elemanları arasındaki farka göre Toplam Boşluk matrisi Eşitlik (21) kullanılarak hesaplanmıştır. Toplam boşluk matrisi değerleri Tablo 9'da gösterilmiştir.

Tablo 9. MAIRCA yöntemi için toplam boşluk matrisi

\begin{tabular}{ccccccccccc}
\hline $\mathrm{P}(\mathrm{i})$ & \multicolumn{10}{c}{ Kriterler } \\
\hline Alternatifler & $\mathrm{C}_{1}$ & $\mathrm{C}_{2}$ & $\mathrm{C}_{3}$ & $\mathrm{C}_{4}$ & $\mathrm{C}_{5}$ & $\mathrm{C}_{6}$ & $\mathrm{C}_{7}$ & $\mathrm{C}_{8}$ & $\mathrm{C}_{9}$ & $\mathrm{C}_{10}$ \\
\hline $\mathrm{A}_{1}$ & 0,0139 & 0,0146 & 0,0132 & 0,0098 & 0,0112 & 0,0043 & 0,0076 & 0,0104 & 0,0091 & 0,0071 \\
\hline $\mathrm{A}_{2}$ & 0,0132 & 0,0152 & 0,0143 & 0,0000 & 0,0000 & 0,0000 & 0,0014 & 0,0026 & 0,0039 & 0,0000 \\
\hline $\mathrm{A}_{3}$ & 0,0072 & 0,0145 & 0,0147 & 0,0011 & 0,0038 & 0,0095 & 0,0108 & 0,0103 & 0,0000 & 0,0097 \\
\hline $\mathrm{A}_{4}$ & 0,0109 & 0,0055 & 0,0094 & 0,0005 & 0,0001 & 0,0009 & 0,0007 & 0,0000 & 0,0027 & 0,0084 \\
\hline $\mathrm{A}_{5}$ & 0,0165 & 0,0149 & 0,0000 & 0,0030 & 0,0104 & 0,0130 & 0,0002 & 0,0107 & 0,0037 & 0,0097 \\
\hline $\mathrm{A}_{6}$ & 0,0168 & 0,0036 & 0,0062 & 0,0043 & 0,0108 & 0,0035 & 0,0039 & 0,0037 & 0,0033 & 0,0071 \\
\hline $\mathrm{A}_{7}$ & 0,0000 & 0,0085 & 0,0114 & 0,0042 & 0,0072 & 0,0086 & 0,0016 & 0,0089 & 0,0075 & 0,0071 \\
\hline $\mathrm{A}_{8}$ & 0,0160 & 0,0135 & 0,0147 & 0,0056 & 0,0041 & 0,0069 & 0,0000 & 0,0028 & 0,0079 & 0,0043 \\
\hline $\mathrm{A}_{9}$ & 0,0072 & 0,0000 & 0,0154 & 0,0070 & 0,0115 & 0,0060 & 0,0002 & 0,0064 & 0,0062 & 0,0097 \\
\hline
\end{tabular}

Her alternatif için Eşitlik (22)'ye göre kriter fonksiyonları son değerleri Tablo 9' da gösterilen değerlerden elde edilmiştir ve Tablo 10’ da gösterilmiştir. Ayrıca Eşitlik (23) kullanılarak Baskınlık Eşik Değeri 0,099 olarak hesaplanmıştır. Eşitlik (24)'te gösterilen en iyi ve en kötü sıradaki alternatifin kriter fonksiyonlarına göre hesaplanan Baskınlık İndeksi değerleri de Tablo 10'da gösterilmiştir.

Tablo 10. MAIRCA yöntemi için kriter fonksiyonları ve baskınlık indeksleri

\begin{tabular}{cccc}
\hline Alternatif & Kriter fonksiyonu & Siralama & Baskınlık indeksi \\
\hline $\mathrm{A}_{1}$ & 0,1012 & 9 & - \\
\hline $\mathrm{A}_{2}$ & 0,0506 & 2 & 0,2384 \\
\hline $\mathrm{A}_{3}$ & 0,0816 & 7 & 0,4257 \\
\hline $\mathrm{A}_{4}$ & 0,0391 & 1 & 0,1136 \\
\hline $\mathrm{A}_{5}$ & 0,0821 & 8 & 0,6140 \\
\hline $\mathrm{A}_{6}$ & 0,0632 & 3 & 0,2566 \\
\hline $\mathrm{A}_{7}$ & 0,0650 & 4 & 0,3017 \\
\hline $\mathrm{A}_{8}$ & 0,0758 & 6 & 0,4200 \\
\hline $\mathrm{A}_{9}$ & 0,0696 & 5 & 0,3633 \\
\hline
\end{tabular}


Tablo 10’da gösterilen Baskınlık İndeksi değerlerinin hepsi Baskınlık Eşik Değeri’nden büyüktür. Bu nedenle alternatiflerin ilk ve nihai sıralamaları arasında bir fark yoktur. MAIRCA yöntemi sonuçlarına göre alternatiflerin sıralamaları $\mathrm{A}_{4}>\mathrm{A}_{2}>\mathrm{A}_{6}>\mathrm{A}_{7}>\mathrm{A}_{9}>\mathrm{A}_{8}>\mathrm{A}_{3}>\mathrm{A}_{5}>\mathrm{A}_{1}$ olarak elde edilmiştir.

\section{Sonuç ve değerlendirme}

Akademik çalışmalar hem araştırmacıların hem de üniversitelerin performans ölçümünde kullanılan temel göstergelerden biridir. Araştırmacılar hem çalışmalarının bilime katkısı hem de kariyer gelecekleri açısından dergi seçimine önem vermektedirler. Doğru dergi seçimi çalışmanın görünürlüğünü ve etkililiğini arttıracaktır. Dergi seçim süreci, ele alınan kriter ve alternatif yapısı nedeniyle ÇKKV ile ele alınabilmektedir. Bu süreçte karar vermeyi sadece oran ölçeğine dayanan objektif veriler ile ele almak gerçeği yansıtmayacaktır. Aralık ölçeğine dayanan sübjektif veriler ile sürecin ele alınması gerçek hayata daha uygun modellerin elde edilmesini sağlayacaktır. Klasik, Bulanık, Sezgisel Bulanık ve Neutrosophic küme teorilerine kıyasla Plithogenic küme teorisi gerçek hayattaki daha fazla değişkenin modele dâhil edilmesine imkân sağlamaktadır. Bu nedenle bu çalışmada kriter ağırlıklarının belirlenmesinde ve alternatiflerin sübjektif kriterler açısından değerlendirilmesinde Plithogenic küme teorisi kullanılmıştır. Bu çalışmada ilk defa Plithogenic küme teorisinden faydalanılarak dergi seçim sürecine uygun çözüm modeli önerisi yapılmıştır. Kriter ağırlıkları belirlenirken karar vericilerin kriterler hakkındaki ortak düşüncelerine göre Çelişki Dereceleri belirlenerek Plithogenic küme teorisi sürece dâhil edilmiştir. Ayrıca alternatifler kıyaslanırken karar vericilerin akademik tecrübelerine, yayın sayılarına ve kişilik özelliklerine göre Çelişki Dereceleri belirlenmiştir.

$\mathrm{Bu}$ çalışma ile araştırmacılara dergi seçim sürecinde karar vermelerine yardımcı olacak model önerisinde bulunulması amaçlanmıştır. Bu amaçla literatürde yapılan çalışmaların incelenmesi sonucunda modelde kullanılan kriterler sübjektif ve objektif olmak üzere iki kısımda belirlenmiştir. Kriterlerin ağırlık değerleri hiyerarşik yapısı nedeniyle AHP yöntemi ile belirlenmiştir. Alternatiflerin sıralanması ise literatürde yeni ve güncel yöntemlerden biri olan MAIRCA yöntemi ile yapılmıştır. Alternatif olarak belirlenen dokuz dergi, üç karar verici tarafından on kriter açısından değerlendirilmiştir. MAIRCA yöntemine göre alternatif sıralamaları arasındaki istikrar Baskınlık İndeksi ile sağlanmıştır ve önerilen model ile alternatifler sıralanmıştır.

Baskınlık İndeksi değerleri ilk alternatifin sıralaması için istikrar sağlıyorsa diğer alternatifler için istikrar sağlaması kaçınılmazdır. Dolayısıyla ilk alternatif istikrarlı ise geriye kalan alternatifler için istikrar hesaplamaları yeni alternatif sayısı ile tekrar edilmelidir. Ancak alternatif sayısı azaldıkça eşik değer yükselmektedir. MAIRCA yöntemi için Baskınlık İndeksi hesaplamalarının doğru olmadığı söylenebilir. Baskınlık İndeksi hesaplamaları için bahsedilen hususlar dikkate alınarak düzeltme yapılması etkinliğini arttıracaktır.

Gelecek çalışmalarda farklı ÇKKV yöntemleri ile bu çalışmada sunulan model girdileri kullanılarak sonuçlar hem ağırlık değerleri hem de alternatif sıralamaları açısından karşılaştırılabilir. Plithogenic küme teorisi farklı karar verme problemlerinde karar vericiler ile ilgili farklı değişkenlerin modele dâhil edilmesi için kullanılabilir ve son olarak Çelişki Derecesi'nin sıralamalara etkisi duyarlılık analizi ile incelenebilir.

\section{Yazarların katkı oranı beyanı}

A. Özçil makalenin veri toplama, veri analizi, raporlaştırma ve diğer aşamalarından sorumlu olduğunu beyan eder.

\section{Çıkar çatışması}

Bu çalışmada yazar tarafından herhangi bir çıkar çatışması belirtilmemiştir.

\section{Etik kurul onayı}

$\mathrm{Bu}$ araştırma insanlarla veya insanlar üzerinde yapılan deney, inceleme ve alan araştırması kapsamında olmadığg için Etik Kurulu Onay belgesi gerekmemektedir. Tüm sorumluluk yazara aittir.

\section{Teşekkür}

Bu çalışmanın ortaya çıkmasında yaptıkları katkı ve ayırdıkları zaman için emeği geçen saygıdeğer hakemlere, yayın sürecini yöneten meslektaşlarıma, çok değerli dostlarım Tayfun ÖZTAŞ ve Gülin Zeynep ÖZTAŞ’a en içten dileklerimle teşekkürlerimi sunarım. 


\section{Kaynakça}

Abastante, F., Corrente, S., Greco, S., Ishizaka, A., and Lami, I. M. (2019). A New Parsimonious AHP Methodology: Assigning Priorities to Many Objects by Comparing Pairwise Few Reference Objects. Expert Systems with Applications, 127, 109-120.

Abdel-Basset, M., and Mohamed, R. (2020). A Novel Plithogenic TOPSIS-CRITIC Model for Sustainable Supply Chain Risk Management. Journal of Cleaner Production, 247, 119586, 1-15.

Abdel-Basset, M., Ding, W., Mohamed, R., and Metawa, N. (2020). An Integrated Plithogenic MCDM Approach for Financial Performance Evaluation of Manufacturing Industries. Risk Management, 22(3), 192-218.

Abdel-Basset, M., El-Hoseny, M., Gamal, A., and Smarandache, F. (2019). A Novel Model for Evaluation Hospital Medical Care Systems Based on Plithogenic Sets. Artificial Intelligence in Medicine, 100, 101710, 1-8.

Abdel-Basset, M., Mohamed, R., Elhoseny, M., and Chang, V. (2020). Evaluation Framework for Smart Disaster Response Systems in Uncertainty Environment. Mechanical Systems and Signal Processing, 145, 106941, 1-18.

Abdel-Basset, M., Mohamed, R., Zaied, A. E. N. H., and Smarandache, F. (2019). A Hybrid Plithogenic Decision-Making Approach with Quality Function Deployment for Selecting Supply Chain Sustainability Metrics. Symmetry, 11(7), 1-21.

Abdel-Basset, M., Mohamed, R., Zaied, A. E. N. H., Gamal, A., and Smarandache, F. (2020). Solving the Supply Chain Problem Using the Best-Worst Method Based on a Novel Plithogenic Model (Editors: Smarandache, F, Abdel-Basset M. Optimization Theory Based on Neutrosophic and Plithogenic Sets, 1-19). Massachusetts: Academic Press.

Adar, T. ve Delice, E. K. (2019). New Integrated Approaches Based on MC-HFLTS for Healthcare Waste Treatment Technology Selection. Journal of Enterprise Information Management, 32(4), 688-711.

Algarín, C. R., Llanos, A. P., and Castro, A. O. (2017). An Analytic Hierarchy Process Based Approach for Evaluating Renewable Energy Sources. International Journal of Energy Economics and Policy, 7(4), 38-47.

Ayçin, E. (2020). Personel Seçim Sürecinde CRITIC ve MAIRCA Yöntemlerinin Kullanılması. İşletme, 1(1), 1-12.

Ayçin, E. ve Güçlü, P. (2020). BIST ticaret Endeksinde Yer Alan İşletmelerin Finansal Performanslarının Entropi ve MAIRCA Yöntemleri ile Değerlendirilmesi. Muhasebe ve Finansman Dergisi, 85, 287-312.

Aydın, Y. (2020). Bütünleşik CRITIC ve MAIRCA Yöntemleri ile Kamu Sermayeli Bankalarının Performans Analizi. Finans Ekonomi ve Sosyal Araştırmalar Dergisi, 5(4), 829-841.

Chatterjee, K., Pamucar, D., and Zavadskas, E. K. (2018). Evaluating the Performance of Suppliers Based on Using the R'AMATEL-MAIRCA Method for Green Supply Chain Implementation in Electronics Industry. Journal of Cleaner Production, 184, 1-58.

Cheng, E. W., and Li, H. (2001) Analytic Hierarchy Process. Measuring Business Excellence, 5(3), 30-36.

Dalton, M. (2013). A Dissemination Divide? The Factors that Influence the Journal Selection Decision of Library and Information Studies (LIS) Researchers and Practitioners. Library and Information Research, 37(5), 33-57.

Gayen, S., Smarandache, F., Jha, S., Singh, M. K., Broumi, S., and Kumar, R. (2020). Introduction to Plithogenic Subgroup (Editors: Smarandache F, Broumi S., Neutrosophic Graph Theory and Algorithms, 213-259). Pensilvanya: IGI Global.

Gigović, L., Pamučar, D., Bajić, Z., and Milićević, M. (2016). The Combination of Expert Judgment and GIS-MAIRCA Analysis for the Selection of Sites for Ammunition Depots. Sustainability, 8(4), 372, 1-30.

Gomathy, S., Nagarajan, D., Broumi, S., and Lathamaheswari, M. (2020). Plithogenic Sets and Their Application in Decision Making. Neutrosophic Sets and Systems, 38, 453-469.

Grida, M., Mohamed, R., and Zaied, A. N. H. (2020). Evaluate the Impact of COVID-19 Prevention Policies on Supply Chain Aspects under Uncertainty. Transportation Research Interdisciplinary Perspectives, 8, 100240, 1-8.

Hamurcu, M. ve Eren, T. (2017). Science Citation Index (SCI) Kapsamında Dergi Seçimi için Analitik Ağ Süreci Yönteminin Kullanılmas1. Harran Üniversitesi Mühendislik Dergisi, 2(2), 54-70.

He, C., and Pao, M. L. (1986). A Discipline-Specific Journal Selection Algorithm. Information Processing \& Management, 22(5), 405-416.

Hilorme, T., Tkach, K., Dorenskyi, O., Katerna, O., and Durmanov, A. (2019). Decision Making Model of Introducing Energy-Saving Technologies Based on the Analytic Hierarchy Process. Journal of Management Information and Decision Sciences, 22(4), 489-494.

Kara, Y. (2019). Quality of Life Measurement: the Application of Analytic Hierarchy Process Method. Eurasian Journal of Social and Economic Research, 6(3), 659-665.

Klingner, J. K., Scanlon, D., and Pressley, M. (2005). How to Publish in Scholarly Journals. Educational Researcher, 34(8), $14-20$.

Knight, L. V., and Steinbach, T. A. (2008). Selecting an Appropriate Publication Outlet: a Comprehensive Model of Journal Selection Criteria for Researchers in a Broad Range of Academic Disciplines. Int. Journal of Doctoral Studies, 3, 59-79.

Korpela, J., and Tuominen, M. (1996). A Decision Aid in Warehouse Site Selection. International Journal of Production Economics, 45(1-3), 169-180. 
Korucuk, S., Demir, E., Karamasa, C., and Stević, Ž. (2020). Determining the Dimensions of the Innovation Ability in Logistics Sector by Using Plithogenic-Critic Method: an Application in Sakarya Province. Int. Review, (1-2), 119-127.

Kuo, R. J., Chi, S. C., and Kao, S. S. (1999). A Decision Support System for Locating Convenience Store through Fuzzy AHP. Computers \& Industrial Engineering, 37(1-2), 323-326.

Kutlu Gündoğdu, F. K., and Kahraman, C. (2020). A Novel Spherical Fuzzy Analytic Hierarchy Process and its Renewable Energy Application. Soft Computing, 24(6), 4607-4621.

Lai, V. S., Wong, B. K., and Cheung, W. (2002). Group Decision Making in a Multiple Criteria Environment: a Case Using the AHP in Software Selection. European Journal of Operational Research, 137(1), 134-144.

Li, Z., and Zhao, S. (2014, July). A Hybrid Fuzzy Multi-Criteria Group Decision Making and Statistical Method for Scientific Journal Evaluation. Seventh International Joint Conference on Computational Sciences and Optimization (s. 670-674). Beijing: Institute of Electrical and Electronics Engineers.

Ömürbek, N. ve Aksoy, E. (2016). Bir Petrol Şirketinin Çok Kriterli Karar Verme Teknikleri ile Performans Değerlendirmesi. Süleyman Demirel Üniversitesi İktisadi ve İdari Bilimler Fakültesi Dergisi, 21(3), 723-756.

Özçil, A., Tuş, A., Öztaş, G. Z., Adal1, E. A., and Öztaş, T. (2020, July). The Novel Integrated Model of Plithogenic Sets and MAIRCA Method for MCDM Problems. International Conference on Intelligent and Fuzzy Systems (s. 733-741). İzmir: Springer, Cham.

Özdağoğlu, A., Keleş, M. K. ve Işıldak, B. (2020). Isparta Süleyman Demirel Havalimanını Kullanan Havayolu Firmaları Performanslarının BWM, MAIRCA ve MABAC ile Değerlendirilmesi. Uluslararası İktisadi ve İdari İncelemeler Dergisi, (29), 175-194.

Öztaş, G. Z., Adal1, E. A., Tuş, A., Öztaş, T., and Özçil, A. (2020, July) An Alternative Approach for Performance Evaluation: Plithogenic Sets and DEA. International Conference on Intelligent and Fuzzy Systems (s. 742-749). İzmir: Springer, Cham.

Pamučar, D., Lukovac, V., Božanić, D., and Komazec, N. (2018). Multi-Criteria FUCOM-MAIRCA Model for the Evaluation of Level Crossings: Case Study in the Republic of Serbia. Operational Research in Engineering Sciences: Theory and Applications, 1(1), 108-129.

Pamučar, D., Mihajlović, M., Obradović, R., and Atanasković, P. (2017). Novel Approach to Group Multi-Criteria Decision Making Based on Interval Rough Numbers: Hybrid DEMATEL-ANP-MAIRCA Model. Expert Systems with Applications, 88, 58-80.

Pamučar, D., Vasin, L., and Lukovac, L. (2014). Selection of Railway Level Crossings for Investing in Security Equipment Using Hybrid DEMATEL-MARICA Model. XVI International Scientific-Expert Conference on Railway (s. 89-92). Niš: University of Niš Faculty of Mechanical Engineering.

Quek, S. G., Selvachandran, G., Smarandache, F., Vimala, J., Le, S. H., Bui, Q. T., and Gerogiannis, V. C. (2020). Entropy Measures for Plithogenic Sets and Applications in Multi-Attribute Decision Making. Mathematics, 8(6), 965, 1-17.

Saaty, R. W. (1987). The Analytic Hierarchy Process - What it is and How it is Used. Mathematical modelling, 9(3-5), 161176.

Saaty, T. L. (1990). How to Make a Decision: the Analytic Hierarchy Process. European Journal of Operational Research, 48(1), 9-26.

Saaty, T. L. (2008). Decision Making with the Analytic Hierarchy Process. Int. Journal of Services Sciences, 1(1), 83-98.

Saaty, T. L., and Vargas, L. S. (2012). Models, Methods, Concepts \& Applications of the Analytic Hierarchy Process (Second Edition). New York: Springer.

Schniederjans, M. J., and Santhanam, R. (1989). A Zero-One Goal Programming Approach for the Journal Selection and Cancellation Problem. Computers \& Operations Research, 16(6), 557-565.

Smarandache, F. (2017). Plithogeny, Plithogenic Set, Logic, Probability, and Statistics. Brussels: The University of New Mexico Digital Repository.

Smarandache, F. (2018). Plithogenic Set, an Extension of Crisp, Fuzzy, Intuitionistic Fuzzy, and Neutrosophic SetsRevisited. Neutrosophic Sets and Systems, 21, 153-166.

Soba, M., Şimşek, A., Erdin, E. ve Can, A. (2016). AHP Temelli Vikor Yöntemi ile Doktora Öğrenci Seçimi. Dumlupınar Üniversitesi Sosyal Bilimler Dergisi, (50), 109-132.

TÜBİTAK. (2021). Uluslararası Bilimsel Yayınları Teşvik Programı. https://cabim.ulakbim.gov.tr/ubyt/ [Erişim Tarihi: 12.03.2021].

Ulutaş, A. (2019). SWARA ve MAIRCA Yöntemleri ile Catering Firmasi Seçimi. Business \& Management Studies: An International Journal, 7(4), 1467-1479.

Unutmaz Durmuşoğlu, Z. D., and Durmuşoğlu, A. (2021). A TOPSIS Model for Understanding the Authors Choice of Journal Selection. Scientometrics, 126(1), 521-543.

Uysal, H. (2012). The Critical Role of Journal Selection in Scholarly Publishing: a Search for Journal Options in LanguageRelated Research Areas and Disciplines. Dil ve Dilbilimi Çalışmaları Dergisi, 8(1), 50-95. 
A. Özçil

\section{Ekler}

Tablo 11. Sübjektif kriterler için ikili karşılaştırmalar ve çelişki dereceleri

\begin{tabular}{|c|c|c|c|c|c|c|}
\hline \multirow{2}{*}{ KV } & \multirow{2}{*}{ Kriter } & \multicolumn{3}{|c|}{ İkili Karşılaştırmalar } & \multirow{2}{*}{$\begin{array}{l}\text { Çelişki Dere- } \\
\text { cesi }\end{array}$} & \multirow{2}{*}{$\begin{array}{l}\text { Tutarlılik } \\
\text { Oranı }\end{array}$} \\
\hline & & $\mathrm{C}_{1}$ & $\mathrm{C}_{2}$ & $\mathrm{C}_{3}$ & & \\
\hline \multirow{3}{*}{$\mathrm{KV}_{1}$} & $\mathrm{C}_{1}$ & $\mathrm{E}$ & $\mathrm{BF}$ & KD & 0,00 & \multirow{3}{*}{0,030} \\
\hline & $\mathrm{C}_{2}$ & $\mathrm{D}$ & $\mathrm{E}$ & Ç & 0,33 & \\
\hline & $\mathrm{C}_{3}$ & ÇD & $\mathrm{D}$ & $\mathrm{E}$ & 0,66 & \\
\hline \multirow{3}{*}{$\mathrm{KV}_{2}$} & $\mathrm{C}_{1}$ & $\mathrm{E}$ & $\mathrm{BF}$ & ÇF & 0,00 & \multirow{3}{*}{0,006} \\
\hline & $\mathrm{C}_{2}$ & $\mathrm{BA}$ & $\mathrm{E}$ & $\mathrm{BF}$ & 0,33 & \\
\hline & $\mathrm{C}_{3}$ & ÇD & BA & $\mathrm{E}$ & 0,66 & \\
\hline \multirow{3}{*}{$\mathrm{KV}_{3}$} & $\mathrm{C}_{1}$ & $\mathrm{E}$ & $\mathrm{BF}$ & KD & 0,00 & \multirow{3}{*}{0,066} \\
\hline & $\mathrm{C}_{2}$ & $\mathrm{D}$ & $\mathrm{E}$ & ÇF & 0,33 & \\
\hline & $\mathrm{C}_{3}$ & KA & $\mathrm{D}$ & $\mathrm{E}$ & 0,66 & \\
\hline
\end{tabular}

Tablo 12. Sübjektif kriterler için Plithogenic birleştirilmiş değerler

\begin{tabular}{cccc}
\hline Kriter & $\mathrm{C}_{1}(\mathrm{~T}, \mathrm{I}, \mathrm{F})$ & $\mathrm{C}_{2}(\mathrm{~T}, \mathrm{I}, \mathrm{F})$ & $\mathrm{C}_{3}(\mathrm{~T}, \mathrm{I}, \mathrm{F})$ \\
\hline $\mathrm{C}_{1}$ & $(0,125,0,400,0,784)$ & $(0,475,0,400,0,412)$ & $(0,926,0,125,0,012)$ \\
\hline $\mathrm{C}_{2}$ & $(0,036,0,675,0,552)$ & $(0,373,0,400,0,525)$ & $(0,820,0,275,0,104)$ \\
\hline $\mathrm{C}_{3}$ & $(0,004,0,850,0,190)$ & $(0,216,0,675,0,323)$ & $(0,620,0,400,0,287)$ \\
\hline
\end{tabular}

Tablo 13. Dergi göstergesi kriterleri için ikili karşılaştırmalar ve çelişki dereceleri

\begin{tabular}{|c|c|c|c|c|c|c|c|}
\hline \multirow[t]{2}{*}{ KV } & \multirow[t]{2}{*}{ Kriter } & \multicolumn{4}{|c|}{ İkili karş1laştırmalar } & \multirow[t]{2}{*}{ Çelişki derecesi } & \multirow[t]{2}{*}{ Tutarlılık oranı } \\
\hline & & $\mathrm{C}_{4}$ & $\mathrm{C}_{5}$ & $\mathrm{C}_{6}$ & $\mathrm{C}_{7}$ & & \\
\hline \multirow{4}{*}{$\mathrm{KV}_{1}$} & $\mathrm{C}_{4}$ & $E$ & ÇD & BA & BF & 0,00 & \multirow[t]{4}{*}{0,005} \\
\hline & $\mathrm{C}_{5}$ & ÇF & $\mathrm{E}$ & $\mathrm{C}$ & $\mathrm{KD}$ & 0,25 & \\
\hline & $\mathrm{C}_{6}$ & $\mathrm{BF}$ & ÇD & E & Ç & 0,25 & \\
\hline & $\mathrm{C}_{7}$ & BA & KA & $\mathrm{D}$ & $\mathrm{E}$ & 0,50 & \\
\hline \multirow[t]{4}{*}{$\mathrm{KV}_{2}$} & $\mathrm{C}_{4}$ & $\mathrm{E}$ & $\mathrm{BF}$ & $\mathrm{BA}$ & Ç & 0,00 & \multirow[t]{4}{*}{0,029} \\
\hline & $\mathrm{C}_{5}$ & $\mathrm{BA}$ & $\mathrm{E}$ & $\mathrm{D}$ & $\mathrm{BF}$ & 0,25 & \\
\hline & $\mathrm{C}_{6}$ & $\mathrm{BF}$ & Ç & $E$ & KD & 0,25 & \\
\hline & $\mathrm{C}_{7}$ & $\mathrm{D}$ & BA & KA & $\mathrm{E}$ & 0,50 & \\
\hline \multirow[t]{4}{*}{$\mathrm{KV}_{3}$} & $\mathrm{C}_{4}$ & $\mathrm{E}$ & BA & ÇD & ÇD & 0,00 & \multirow[t]{4}{*}{0,052} \\
\hline & $\mathrm{C}_{5}$ & $\mathrm{BF}$ & $\mathrm{E}$ & $\mathrm{D}$ & $\mathrm{BA}$ & 0,25 & \\
\hline & $\mathrm{C}_{6}$ & ÇF & Ç & $\mathrm{E}$ & $\mathrm{BF}$ & 0,25 & \\
\hline & $\mathrm{C}_{7}$ & ÇF & BF & BA & $\mathrm{E}$ & 0,50 & \\
\hline
\end{tabular}

Tablo 14. Dergi göstergesi kriterleri için Plithogenic birleştirilmiş değerler

\begin{tabular}{ccccc}
\hline & $\mathrm{C}_{4}(\mathrm{~T}, \mathrm{I}, \mathrm{F})$ & $\mathrm{C}_{5}(\mathrm{~T}, \mathrm{I}, \mathrm{F})$ & $\mathrm{C}_{6}(\mathrm{~T}, \mathrm{I}, \mathrm{F})$ & $\mathrm{C}_{7}(\mathrm{~T}, \mathrm{I}, \mathrm{F})$ \\
\hline $\mathrm{C}_{4}$ & $(0,125,0,400,0,784)$ & $(0,217,0,600,0,396)$ & $(0,148,0,700,0,359)$ & $(0,425,0,575,0,175)$ \\
\hline $\mathrm{C}_{5}$ & $(0,192,0,400,0,559)$ & $(0,313,0,400,0,586)$ & $(0,217,0,600,0,332)$ & $(0,575,0,425,0,225)$ \\
\hline $\mathrm{C}_{6}$ & $(0,288,0,300,0,559)$ & $(0,352,0,425,0,290)$ & $(0,313,0,400,0,586)$ & $(0,700,0,300,0,200)$ \\
\hline $\mathrm{C}_{7}$ & $(0,096,0,425,0,496)$ & $(0,230,0,575,0,360)$ & $(0,152,0,700,0,315)$ & $(0,500,0,400,0,400)$ \\
\hline
\end{tabular}

Tablo 15. Diğer göstergesi kriterleri için ikili karşılaştırmalar ve çelişki dereceleri

\begin{tabular}{|c|c|c|c|c|c|c|}
\hline \multirow{2}{*}{$\mathrm{KV}$} & \multirow{2}{*}{ Kriter } & \multicolumn{3}{|c|}{ İkili Karşılaştırmalar } & \multirow{2}{*}{ Çelişki Derecesi } & \multirow{2}{*}{ Tutarlılık Oran } \\
\hline & & $\mathrm{C}_{8}$ & $\mathrm{C}_{9}$ & $\mathrm{C}_{10}$ & & \\
\hline \multirow{3}{*}{$\mathrm{KV}_{1}$} & $\mathrm{C}_{8}$ & $\mathrm{E}$ & ÇF & KD & 0,00 & \multirow{3}{*}{0,071} \\
\hline & $\mathrm{C}_{9}$ & ÇD & $\mathrm{E}$ & $\mathrm{BF}$ & 0,33 & \\
\hline & $\mathrm{C}_{10}$ & KA & $\mathrm{BA}$ & $\mathrm{E}$ & 0,66 & \\
\hline \multirow{3}{*}{$\mathrm{KV}_{2}$} & $\mathrm{C}_{8}$ & $\mathrm{E}$ & Ç & KD & 0,00 & \multirow{3}{*}{0,025} \\
\hline & $\mathrm{C}_{9}$ & $\mathrm{D}$ & $\mathrm{E}$ & $\mathrm{BF}$ & 0,33 & \\
\hline & $\mathrm{C}_{10}$ & KA & $\mathrm{BA}$ & $\mathrm{E}$ & 0,66 & \\
\hline \multirow{3}{*}{$\mathrm{KV}_{3}$} & $\mathrm{C}_{8}$ & $\mathrm{E}$ & $\mathrm{BF}$ & KD & 0,00 & \multirow{3}{*}{0,074} \\
\hline & $\mathrm{C}_{9}$ & $\mathrm{D}$ & $\mathrm{E}$ & Ç & 0,33 & \\
\hline & $\mathrm{C}_{10}$ & KA & BA & $\mathrm{E}$ & 0,66 & \\
\hline
\end{tabular}


Tablo 16. Diğer gösterge kriterleri için Plithogenic birleştirilmiş değerler

\begin{tabular}{cccc}
\hline Kriter & $\mathrm{C}_{8}(\mathrm{~T}, \mathrm{I}, \mathrm{F})$ & $\mathrm{C}_{9}(\mathrm{~T}, \mathrm{I}, \mathrm{F})$ & $\mathrm{C}_{10}(\mathrm{~T}, \mathrm{I}, \mathrm{F})$ \\
\hline $\mathrm{C}_{8}$ & $(0,125,0,400,0,784)$ & $(0,564,0,325,0,311)$ & $(0,940,0,100,0,000)$ \\
\hline $\mathrm{C}_{9}$ & $(0,018,0,725,0,424)$ & $(0,373,0,400,0,525)$ & $(0,757,0,350,0,162)$ \\
\hline $\mathrm{C}_{10}$ & $(0,001,0,900,0,000)$ & $(0,280,0,600,0,412)$ & $(0,620,0,400,0,287)$ \\
\hline
\end{tabular}

Tablo 17. Alternatiflerin sübjektif kriterler için ikili karşılaştırmaları

\begin{tabular}{|c|c|c|c|c|c|}
\hline \multirow{2}{*}{ KV } & \multirow{2}{*}{ Alternatif } & \multicolumn{3}{|c|}{ Kriter } & \multirow{2}{*}{ Çelişki Dereces } \\
\hline & & $\mathrm{C}_{1}$ & $\mathrm{C}_{2}$ & $\mathrm{C}_{3}$ & \\
\hline \multirow{9}{*}{$\mathrm{KV}_{1}$} & $\mathrm{~A}_{1}$ & $\mathrm{BF}$ & $\mathrm{D}$ & $\mathrm{E}$ & \multirow{9}{*}{0,00} \\
\hline & $\mathrm{A}_{2}$ & $\mathrm{D}$ & $\mathrm{E}$ & $\mathrm{BF}$ & \\
\hline & $\mathrm{A}_{3}$ & ÇF & BA & $\mathrm{E}$ & \\
\hline & $\mathrm{A}_{4}$ & $\mathrm{C}$ & Ç & ÇF & \\
\hline & $\mathrm{A}_{5}$ & BA & $\mathrm{D}$ & KD & \\
\hline & $\mathrm{A}_{6}$ & $\mathrm{E}$ & KD & ÇF & \\
\hline & $\mathrm{A}_{7}$ & $\mathrm{KD}$ & $\mathrm{BF}$ & $\mathrm{E}$ & \\
\hline & $\mathrm{A}_{8}$ & BA & $\mathrm{BF}$ & KA & \\
\hline & $\mathrm{A}_{9}$ & ÇF & $\mathrm{KD}$ & $\mathrm{BA}$ & \\
\hline \multirow{9}{*}{$\mathrm{KV}_{2}$} & $\mathrm{~A}_{1}$ & $\mathrm{BF}$ & ÇD & $\mathrm{E}$ & \multirow{9}{*}{0,25} \\
\hline & $\mathrm{A}_{2}$ & ÇD & BA & $\mathrm{E}$ & \\
\hline & $\mathrm{A}_{3}$ & Ç & $\mathrm{E}$ & $\mathrm{BA}$ & \\
\hline & $\mathrm{A}_{4}$ & $\mathrm{BF}$ & Ç & $\mathrm{BF}$ & \\
\hline & $\mathrm{A}_{5}$ & BA & $\mathrm{D}$ & $\mathrm{KD}$ & \\
\hline & $\mathrm{A}_{6}$ & $\mathrm{BA}$ & ÇF & Ç & \\
\hline & $\mathrm{A}_{7}$ & ÇF & Ç & Ç & \\
\hline & $\mathrm{A}_{8}$ & $\mathrm{D}$ & $\mathrm{E}$ & $\mathrm{D}$ & \\
\hline & $\mathrm{A}_{9}$ & Ç & $\mathrm{KD}$ & $\mathrm{D}$ & \\
\hline \multirow{9}{*}{$\mathrm{KV}_{3}$} & $\mathrm{~A}_{1}$ & $\mathrm{E}$ & KA & $\mathrm{BF}$ & \multirow{9}{*}{0,25} \\
\hline & $\mathrm{A}_{2}$ & KA & $\mathrm{D}$ & BA & \\
\hline & $\mathrm{A}_{3}$ & $\mathrm{BF}$ & $\mathrm{E}$ & $\mathrm{E}$ & \\
\hline & $\mathrm{A}_{4}$ & $\mathrm{BF}$ & ÇF & $\mathrm{BF}$ & \\
\hline & $\mathrm{A}_{5}$ & $\mathrm{D}$ & $\mathrm{D}$ & ÇF & \\
\hline & $\mathrm{A}_{6}$ & BA & Ç & Ç & \\
\hline & $\mathrm{A}_{7}$ & Ç & $\mathrm{C}$ & $\mathrm{BF}$ & \\
\hline & $\mathrm{A}_{8}$ & $\mathrm{D}$ & $\mathrm{E}$ & ÇD & \\
\hline & $\mathrm{A}_{9}$ & $\mathrm{BF}$ & ÇF & $\mathrm{D}$ & \\
\hline
\end{tabular}

Tablo 18. Alternatiflerin sübjektif kriterler için Plithogenic birleştirilmiş değerleri

\begin{tabular}{lccc}
\hline & $\mathrm{C}_{1}(\mathrm{~T}, \mathrm{I}, \mathrm{F})$ & $\mathrm{C}_{2}(\mathrm{~T}, \mathrm{I}, \mathrm{F})$ & $\mathrm{C}_{3}(\mathrm{~T}, \mathrm{I}, \mathrm{F})$ \\
\hline $\mathrm{A}_{1}$ & $(0,180,0,400,0,706)$ & $(0,072,0,825,0,161)$ & $(0,356,0,400,0,537)$ \\
$\mathrm{A}_{2}$ & $(0,006,0,825,0,280)$ & $(0,205,0,600,0,452)$ & $(0,291,0,500,0,504)$ \\
$\mathrm{A}_{3}$ & $(0,336,0,325,0,496)$ & $(0,288,0,450,0,556)$ & $(0,288,0,450,0,556)$ \\
$\mathrm{A}_{4}$ & $(0,252,0,375,0,608)$ & $(0,587,0,250,0,271)$ & $(0,475,0,350,0,396)$ \\
$\mathrm{A}_{5}$ & $(0,048,0,650,0,608)$ & $(0,153,0,700,0,332)$ & $(0,756,0,150,0,075)$ \\
$\mathrm{A}_{6}$ & $(0,080,0,550,0,706)$ & $(0,646,0,225,0,199)$ & $(0,568,0,275,0,290)$ \\
$\mathrm{A}_{7}$ & $(0,504,0,225,0,280)$ & $(0,496,0,325,0,374)$ & $(0,090,0,800,0,180)$ \\
$\mathrm{A}_{8}$ & $(0,036,0,675,0,552)$ & $(0,338,0,400,0,556)$ & $(0,169,0,675,0,374)$ \\
$\mathrm{A}_{9}$ & $(0,336,0,325,0,496)$ & $(0,756,0,150,0,075)$ & \\
\hline
\end{tabular}




\section{Extended Abstract}

\section{Introduction}

Choosing the most accurate and effective journal in academic studies is extremely important in terms of both saving time and increasing productivity. The accessibility, visibility and effectiveness of the selected journal facilitates the dissemination of academic studies. Journal selection process, which is a MCDM problem, can be handled with objective and subjective criteria. Due to the polysemy and uncertainty of the subjective criteria, solutions are sought with different set theories. For this reason, Plithogenic set theory is used in this study to combine decision maker evaluations. Decision maker evaluations denoted by linguistic variables are used both in determining the weight values of the criteria and comparing the alternatives in terms of subjective criteria. The weight values of the criteria determined for the journal selection process are determined by the Analytic Hierarchy Process (AHP) method. The rankings of the alternatives are made according to the Multi Attributive IdealReal Comparative Analysis (MAIRCA) method.

\section{Research purpose}

It is aimed with this study to suggest a model that will help researchers make their decisions in the journal selection process. In addition, the use of Plithogenic set theory in other methods after the aggregation process is exemplified by the AHP and MAIRCA methods.

\section{Methodology}

The flowchart of the journal selection process of a completed article is given in Figure 1.

Figure 1. Journal selection process

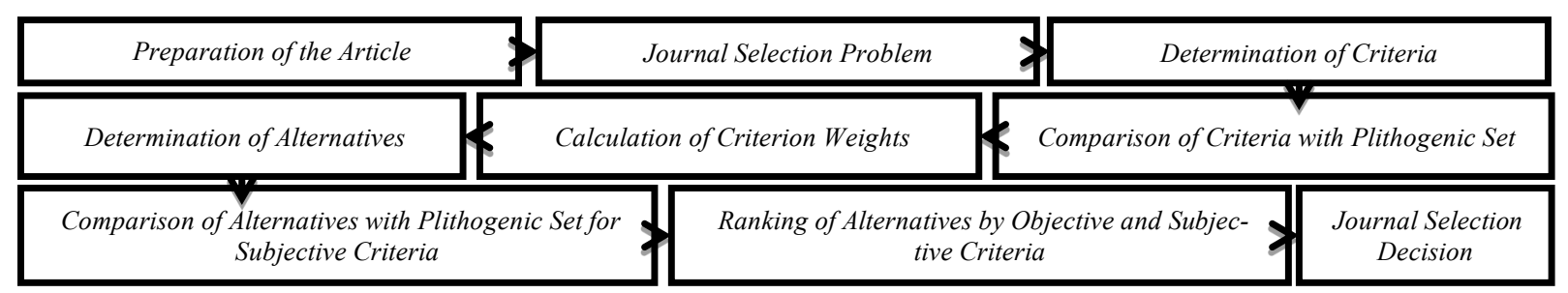

As a result of the examination of the studies in the literature, the criteria used in the model are determined in two parts, subjective and objective. The criteria weights are determined by AHP method due to its hierarchical structure. The ranking of the alternatives is made using the MAIRCA method, which is one of the new and updated methods in the literature. Nine journals determined as alternatives are evaluated by three decision makers in terms of ten criteria. The hierarchical structure of the journal selection process in accordance with the AHP method is shown in Figure 2.

Figure 2. The hierarchical structure of the journal selection process

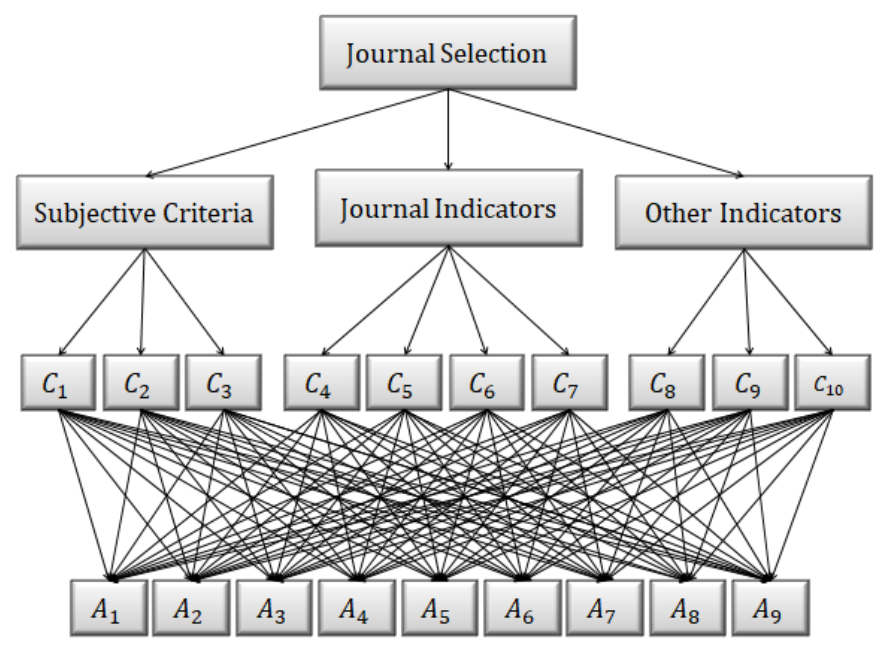

According to the MAIRCA method, the stability among the alternative rankings is provided by the Dominance Index and the alternatives are ranked with the proposed model. 


\section{Literature review}

In the literature, the Plithogenic aggregation operator is used in MCDM methods to combine the evaluations of decision makers. Some sample studies are given below.

Abdel-Basset and Mohamed (2020) discussed the determination and ranking of sustainable supply chain risks of enterprises with Plithogenic aggregation operator, CRITIC and TOPSIS methods. Three risk types identified as alternatives were evaluated in terms of thirty-six criteria and by three decision makers. Grida et al. (2020) made the weighting of the pandemic prevention policies and the ranking of their effects on the supply chain using the Plithogenic aggregation operator, BWM and TOPSIS methods. Three alternatives as policy recommendations were evaluated by four decision makers in terms of nine criteria. Abdel-Basset, Mohamed, Elhoseny, and Chang (2020) determined the weight values of fourteen criteria of the intelligent disaster response system selection problem using the Plithogenic aggregation operator and the AHP method. The ranking results of the five alternatives were compared with the TOPSIS and VIKOR methods.

\section{Findings}

The aggregated Plithogenic weight values of the criteria calculated according to the AHP method are given in Table 1.

Table 1. Local and global weight values for all criteria

\begin{tabular}{|c|c|c|c|c|c|c|c|c|c|c|}
\hline Main Criteria & \multicolumn{3}{|c|}{$\mathrm{G}_{1}$} & \multicolumn{4}{|c|}{$\mathrm{G}_{2}$} & \multicolumn{3}{|c|}{$\mathrm{G}_{3}$} \\
\hline Weight Values & & 0.426 & & & & & & & 0.266 & \\
\hline Sub-Criteria & $\mathrm{C}_{1}$ & $\mathrm{C}_{2}$ & $\mathrm{C}_{3}$ & $\mathrm{C}_{4}$ & $\mathrm{C}_{5}$ & $\mathrm{C}_{6}$ & $\mathrm{C}_{7}$ & $\mathrm{C}_{8}$ & $\mathrm{C}_{9}$ & $\mathrm{C}_{10}$ \\
\hline Local Weights & 0.355 & 0.321 & 0.325 & 0.286 & 0.335 & 0.379 & 0.315 & 0.361 & 0.309 & 0.330 \\
\hline Global Weights & 0.151 & 0.137 & 0.138 & 0.088 & 0.103 & 0.117 & 0.097 & 0.096 & 0.082 & 0.088 \\
\hline
\end{tabular}

All of the Dominance index values are greater than the Dominance Threshold. Therefore, there is no difference between the initial and final rankings of the alternatives. According to the results of the MAIRCA method, the rankings of the alternatives are obtained as $A_{4}>A_{2}>A_{6}>A_{7}>A_{9}>A_{8}>A_{3}>A_{5}>A_{1}$.

According to the MAIRCA method, the stability among the rankings of the alternatives is provided by the dominance index. If the dominance index values provide stability for the ranking of the first alternative, it is inevitable that it provides stability for the other alternatives. Therefore, if the first alternative is stable, the stability calculations for the remaining alternatives should be repeated with the new number of alternatives. However, as the number of alternatives decreases, the threshold value increases. It can be said that the dominance index calculations for the MAIRCA method are not correct. Making corrections considering the mentioned issues for dominance index calculations will increase its efficiency.

\section{Conclusions}

As a result, a decision-making model in which different attribute values are integrated into decision-maker preferences is proposed for the journal selection process. For the first time, a solution model suitable for the journal selection process is proposed by making use of the Plithogenic set theory in this study.

In future studies, using different MCDM methods and model inputs presented in this study, the results can be compared in terms of both weight values and alternative rankings. Plithogenic set theory can be used to include different variables related to decision makers in different decision-making problems, and finally, the effect of the degree of contradiction on rankings can be investigated by sensitivity analysis. 